Department of Economics - FEA/USP

\title{
Choosing the Form of Government: Theory and Evidence from Brazil
}

MARCoS YAMADA NAKAGUMA

WORKING PAPER SERIES № 2013-17 


\title{
Choosing the Form of Government: Theory and Evidence from Brazil
}

Marcos Yamada Nakaguma (nakaguma@usp.br)

\begin{abstract}
:
This paper proposes a model to study the main factors that influence the preferences of different population groups between presidential and parliamentary systems. Our theory suggests that the parliamentary regime leads to a type of fiscal decentralization in the form of more transfers to constituencies. Ceteris paribus, the poor groups in the population tend to prefer a presidential system relatively more than the rich, since the lower quality of their local accountability institutions (e.g. local media and judicial courts) makes them more vulnerable to the expropriation of rents by their legislators. We also show that in order to perform adequately a parliamentary regime depends on the existence of a class of politicians that can be trusted to represent well the interests of voters. Our model is able to account for the main stylized facts emerging from an analysis of referendum data from Brazil.
\end{abstract}

Keywords: Constitutions, political regime, presidential system, parliamentary system.

JEL Codes: D02, D7, H0 


\title{
Choosing the Form of Government: Theory and Evidence from Brazil ${ }^{*}$
}

\author{
Marcos Yamada Nakaguma ${ }^{\dagger}$
}

July, 2013

\begin{abstract}
This paper proposes a model to study the main factors that influence the preferences of different population groups between presidential and parliamentary systems. Our theory suggests that the parliamentary regime leads to a type of fiscal decentralization in the form of more transfers to constituencies. Ceteris paribus, the poor groups in the population tend to prefer a presidential system relatively more than the rich, since the lower quality of their local accountability institutions (e.g. local media and judicial courts) makes them more vulnerable to the expropriation of rents by their legislators. We also show that in order to perform adequately a parliamentary regime depends on the existence of a class of politicians that can be trusted to represent well the interests of voters. Our model is able to account for the main stylized facts emerging from an analysis of referendum data from Brazil.
\end{abstract}

*I would like to thank Massimo Morelli, Alessandra Casella, Navin Kartik and Suresh Naidu for invaluable support and advice. I am also indebted to Patrick Bolton, Rodrigo Bueno, Bruno Giovannetti, Carlos Eduardo Gonçalves, Takakazu Honryo, Ethan Kaplan, Gabriel Madeira, Guilherme Martins, Andrea Mattozzi, Marcos Rangel, Mauro Rodrigues, Bernard Salanié, Hitoshi Shigeoka, Heriberto Tapia, Mariano Tommasi, Sébastien Turban and seminar participants at Columbia Univeristy, EUI, EESP-FGV, PUC-Rio, University of Sao Paulo, University of Siena, the EPCS Meeting (Zurich), the ISNIE Conference (Florence) and the EPSA Conference (Barcelona) for comments and suggestions. I am also grateful to the staff at the Tribunal Superior Eleitoral (TSE) and CESOP-UNICAMP for help with data collection. All errors are my own.

${ }^{\dagger}$ European University Institute and University of Sao Paulo. Email: nakaguma@usp.br. 


\section{Introduction}

The form of government is one of the most important features of the organization of a democracy, as it establishes rules about how the government is to be appointed and removed from office. There are two major systems: a presidential regime, where the executive is directly elected by voters and is guaranteed to stay in office for a fixed term, and a parliamentary regime, where the executive is appointed by the parliament and may be removed if it receives a vote of no confidence. The choice of form of government is a recurrent and controversial issue in many societies, and debates about it should gain further relevance as more countries move to democratic systems and as new democracies gradually consolidate. ${ }^{1}$

Despite the existence of a large literature studying the differences between presidential and parliamentary systems, little attention has been devoted to the question of what determines the choice of form of government. Among the few papers that examine this issue, the focus has been either on the historical context behind the choice (Persson and Tabelini [2003] and Cheibub [2007]) or on the interests of elites to impose a particular regime (Lijphart [1992], Easter [1997] and Robinson and Torvik [2009]). Still, the challenges posed by constitutional design in modern societies make it important that we understand how these issues are perceived by citizens, particularly because such decisions are likely to depend more and more on the population's consent, either informally through protests and public manifestations or formally through referenda.

This paper studies the main factors that determine the constitutional preferences of citizens over the form of government. In order to motivate our theoretical analysis, we first study the case of Brazil, where a referendum in 1993 allowed the population to choose between a presidential and a parliamentary system. In doing so, we rely on a novel dataset consisting of the results of the referendum at municipal level as well as several opinion surveys conducted at that time. This information provides a unique opportunity to observe the constitutional preferences of different population groups and allows us to study the question of choice of the form of government directly from the perspective of citizens.

The analysis of the data reveals a surprising new fact: while the Brazilian population in general voted in favour of a presidential system, there exists a strong positive correlation between income per capita and the percentage of votes cast for a parliamentary regime across municipalities; that is, the poor (rich) groups in the population voted more for a presidential (parliamentary) system. ${ }^{2}$ We further document that among the electorate a common reason for rejecting a parliamentary regime was the absence of direct elections for the executive in connection with a lack of confidence in the congress. The general perception was that corruption was widespread among legislators and that a parliamentary system would further exacerbate the problem. ${ }^{3}$

\footnotetext{
${ }^{1}$ The possibility of a change in the form of government has been recently considered in several countries, including Argentina, Brazil, Chile, Colombia, Egypt, Indonesia, Mexico, Nigeria, the Philippines, South Korea, Tunisia and Turkey (Cheibub [2007]).

${ }^{2}$ Using detailed survey data, we show that this evidence cannot be explained by the fact that the poor individuals simply lacked knowledge about the referendum and, therefore, voted more for a presidential system merely because it represented the status quo.

${ }^{3}$ As in many developing countries, corruption was (and still is) a major concern in Brazil. The magnitude of the
} 
The evidence from Brazil is, in a sense, quite puzzling and the existing papers in the literature (Persson, Roland and Tabelini [1997, 2000] and Robinson and Torvik [2009]) are unable to account for the fact that the poorer citizens were more likely to vote for a presidential system. We propose a theoretical model to explain the general pattern of the referendum results, focusing on a fundamental difference between presidential and parliamentary systems: on the one hand, direct elections for a president allow voters to hold the executive leader directly accountable, but imply that the president may not be removed from office before the next elections; on the other hand, a vote of no confidence transfers to legislators the responsibility for monitoring the executive, but provides a mechanism to replace the prime minister before the end of his term.

Our formal analysis emphasizes that the bargaining power of legislators is larger under parliamentary systems. This enables them to push for higher transfers to constituencies, which in turn expands their own capacity to extract rents. Intuitively, these funds are intended to finance the provision of local public goods (e.g. investment in education), but are also subject to expropriation by legislators. Since the quality of local accountability institutions (e.g. the local media and judicial courts) is heterogeneous across regions, and usually lower in poorer constituencies, the burden of corruption tends to fall disproportionately on the poor population. ${ }^{4,5}$ As a result, a parliamentary system is relatively less attractive to the poor than to the rich.

In a presidential system, on the other hand, the bargaining power of legislators is diminished, which limits the size of transfers and the amount of political rents that they are able to obtain. Now, it is the executive leader who is in a stronger position to extract rents, which he does by deviating resources from the federal budget. At the national level, the executive leader is subject to the control of institutions such as large media outlets, federal prosecutors and investigative agencies, which provide common protection to the population as a whole. As a consequence, the burden of corruption imposed by the executive is distributed more uniformly among voters and there is less dependence on local institutions. ${ }^{6}$

Why should local accountability institutions matter to control federal level legislators? The process of corruption consists of a complex chain of illegal transactions involving several agents,

problem is huge: it is estimated that, every year, at least US $\$ 3.5$ billion (or $1.5 \%$ of Brazil's GDP) are diverted just through corruption from the federal funds transferred to muncipal governments for investment in basic education, health and infrastructure. These estimates are based on audit reports published by the Controladoria-Geral da Uniao (CGU) (Folha de Sao Paulo, 9/4/2011).

${ }^{4}$ In Brazil, the quality of local institutions displays considerable regional variation. For instance, Pinheiro and Cabral (1999) report that members of the judiciary tend to be less prepared in poorer regions, citing the case of a judge who still used old and revoked legislation as basis for his decisions.

${ }^{5}$ This implication of the model is consistent with Ferraz and Finan $(2008,2011)$, who find that the presence of local media (i.e. a radio station or a local newspaper) reduces the incidence of corruption in Brazilian municipalities.

${ }^{6}$ The model captures the idea that the corruption practices of executive leaders tend to be more centralized in nature, impacting broader sectors of the population at the same time. This notion is consistent with several corruption cases uncovered in Latin America and other developing countries in recent decades. For instance, presidents Fernando Collor de Mello (Brazil), Arnoldo Aleman (Nicaragua), Alberto Fujimori (Peru) and Carlos Andres Perez (Venezuela) were all charged with running large corruption schemes, often involving outright expropriation of public funds (e.g. Fujimori was found guilty of giving US\$ 15 million from the Peruvian treasury to his former intelligence service chief) and large scale influence-peddling schemes (e.g. Collor de Mello ran a vast scheme that sold "government favors" all around the country through his campaign treasurer). 
including congressmen, contractors, public servants and mayors. As in many other countries, in Brazil it usually begins when a contractor approaches a congressman to "propose" a project, say, the construction of a bridge, in a municipality where that legislator has strong political influence. The congressman starts to sponsor the project and works to obtain political support in congress, technical and regulatory approvals from government agencies, as well as the disbursement of funds. ${ }^{7}$ Next, at the local level, the procurement process is manipulated, usually with the participation of municipal authorities, in order to ensure that the contract goes to the "right" firm, typically for a value above the market price. Finally, the contractor obtains a profit and distributes rents in the form of bribes, gifts and campaign contributions to the several agents involved in the process. Therefore, expropriation presupposes a series of corrupt acts which take place at the local level. As a consequence, local institutions play an important role in restraining corruption by legislators. For instance, local prosecutors and judges are instrumental in investigating and judging cases of procurement fraud, money laundering and illicit enrichment, which are all crimes committed at the local level.

The model generates other interesting results. We examine how the form of government influences the choice of a national public policy (e.g. a reform of the social security system) in an environment where the policy preference of voters and office-holders, including both the executive leader and legislators, may become misaligned after elections due to an unexpected change in the state of the world. We show that a parliamentary system leads to comparatively better policies for the majority of the population as long as the likelihood that the office-holders remain aligned with their constituencies is large enough. Intuitively, this condition can be interpreted as requiring that the quality of political representation in the society be sufficiently high.

The traditional argument in favor of parliamentarism is that it allows for the possibility of replacing an unpopular or incompetent government prior to elections. ${ }^{8}$ Indeed, many political analysts in Brazil supported a parliamentary regime as being the most "modern" and "flexible" alternative. Nevertheless, our analysis suggests that parliamentarism is also the regime that is most "intensive" in political institutions, in that it requires a strong system of protection against expropriation, particularly at the local level, and a class of politicians that can be trusted to represent well the interests of voters.

This paper is related to a growing literature on endogenous political institutions, including Acemoglu and Robinson (2000), Aghion and Bolton (2003), Aghion, Alesina and Trebbi (2004), Trebbi, Aghion and Alesina (2008), Robinson and Torvik (2009), Ticchi and Vindigni (2010) and Acemoglu, Robinson and Torvik (2011). Among these, Robinson and Torvik (2009) is the study that is most closely related to our work. They also investigate the question of the choice of form

\footnotetext{
${ }^{7}$ See Persico, Silverman and Rodríguez-Pueblita (2011) for examples on how some of these legislators operate to bring funds to their strongholds.

${ }^{8}$ In a recent article entitled "Does Egypt Need a Pharaoh?", Alfred Stepan and Juan Linz argued for the adoption of a parliamentary system in Egypt on the basis that "to elect a president is to commit to one person, generally for at least four years. But it is very uncertain that any person elected today in Egypt would have the same support in even a year. (...) It is also possible that a new president turns out to be incompetent, or is in a permanent minority position and unable to pass legislation".
} 
of government, although their main focus is on the interests of political elites behind the process of constitutional choice. They argue that presidential regimes are prevalent in Africa and Latin America because it is the system that generates most rents to its leaders. ${ }^{9}$

Although the argument put forward by Robinson and Torvik (2009) may well apply to a number of historical cases, our analysis suggests that it cannot be taken as a general explanation for the predominance and persistence of presidential systems in developing countries, especially in Latin America. In this respect, our paper sheds new light on the question of the endogenous choice of form of government by focusing specifically on the interests of the population. We contribute to the literature by providing novel evidence about the constitutional preferences of voters in Brazil. To the best of our knowledge, the present study is the first to use referendum data to examine this important issue.

The results of this paper are also related to Acemoglu and Johnson (2005), who emphasize the fact that different institutions are often closely linked to each other. This feature makes it particularly difficult to isolate the effect of specific aspects of the institutional environment (i.e. the issue of "unbundling institutions"). Interestingly, our model shows that the choice of form of government depends on the quality of the accountability institutions in a society. This result has important implications for empirical and policy-oriented research. For instance, several recent papers have argued that presidentialism leads to more corruption (Lederman, Loayza and Soares [2005], Kunicova and Rose-Ackerman [2005]). However, our analysis of the Brazilian experience suggests that causality might run in the opposite direction; that is, it is possible that countries that are more prone to corruption may also be more likely to adopt presidential systems.

This paper is also connected to a number of studies in comparative politics that have examined the differences between presidential and parliamentary systems. An influential view in this literature is that presidential democracies are inherently less stable and more prone to coups. This notion has been argued by Linz $(1978,1990)$ and Stepan and Skach (1993), among others, based on the fact that the relationship between executive and legislative tends to be more conflictual under presidential regimes. However, many scholars, including Shugart and Carey (1992), Mainwaring and Shugart (1997) and Cheibub (2007), have challenged this view. According to Cheibub (2007), the problem is not that presidential systems are fundamentally flawed, but rather that "they tend to exist in societies where democracies of any type are likely to be unstable". This perspective highlights the fact that to understand the political and economic consequences of each system one must first understand the reasons behind their adoption. The present paper provides a contribution in this direction by highlighting some of the main elements behind the process of constitutional choice.

In the political economy literature, Persson, Roland and Tabellini (1997, 2000) were the first to propose a formal model to compare the performance of presidential and parliamentary regimes. ${ }^{10}$

\footnotetext{
${ }^{9}$ It must be noted that the type of presidentialism considered by Robinson and Torvik (2009) is one with very few checks and balances, where the executive leader has extremely dominant powers, as in the cases of Joseph Mobutu in Zaire and Robert Mugabe in Zimbabwe.

${ }^{10}$ Persson and Tabellini $(2003,2004)$ provide cross-country evidence that presidential systems have smaller gov-
} 
They show that presidential systems are associated with less political rents, while parliamentary systems are associated with more redistribution towards broad population groups and a higher provision of public goods. However, their model assumes that all voters are homogeneous and does not allow for direct elections for president. As such, their framework is unable to account for the stylized facts presented in this paper, particularly the evidence that poor citizens voted more for a presidential regime.

Finally, our analysis highlights the fact that parliamentarism entails a type of fiscal decentralization, in the form of more transfers to constituencies, which increases the need for better accountability institutions at the local level. The present paper is, in this sense, related to a literature on fiscal federalism which also emphasizes the distinction between national and local institutions for the performance of public policies (Prud'homme [1995], Tanzi [1995] and Oates [1999]).

The remainder of this paper is organized as follows. Section 2 provides a brief historical backgroud of the Brazilian referendum and presents the main stylized facts emerging from our empirical analysis. Section 3 introduces the basic setup of the model and discusses its main assumptions. Section 4 solves for a subgame perfect Nash equilibrium of the model. Section 5 presents our main comparative results and section 6 provides a characterization of the constitutional preferences of the various groups of the population. Finally, section 7 concludes the paper.

\section{$2 \quad$ Brazil's Referendum of 1993}

\subsection{Historical Background}

In April 1993, the Brazilian population voted in a referendum to choose between a presidential and a parliamentary system of government. The decision to hold the referendum had been agreed upon five years earlier, during the discussions that led to the democratic constitution of 1988 . The proposal for its realization received strong support among members of the constitutional assembly and served as a compromise solution to the controversial issue that the choice of form of government proved to be. ${ }^{11}$ It was then decided that a presidential system would be provisionally adopted until the referendum in 1993.

The period between the early 80's and mid 90's, which is often referred to as Brazil's "lost decade", was marked by a series of economic problems, beginning with the debt crisis of the 80's and followed by a long period of stagflation. At the same time, the country faced important difficulties related to its fragmented party system and widespread corruption in both the executive and the congress. Indeed, the first popularly elected president after the military regime, Fernando Collor de Mello, was impeached in 1992 amid accusations of running a vast influence-peddling

ernments, while parliamentary regimes have more persistent fiscal outcomes (i.e. increases in government spending during downturns are not reversed during booms).

${ }^{11}$ The presidential regime received active support from the goverment of president Jose Sarney (1985-1990), who hoped to stay in office for the remainder of his term. It also received the advocacy of parties with strong candidates in the next presidential elections, including the PT (Luis Inacio Lula da Silva) and the PDT (Leonel Brizola). For more historical details, see Silva (1990) and Bonavides and Andrade (2004). 
scheme. Around the same time, a massive corruption scandal was uncovered involving at least forty three members of the congress, several public officials and a cartel of construction firms that controlled the procurement of public works in several parts of the country. ${ }^{12}$

In this context, the debates around the referendum focused broadly on two main themes: the issue of governability, i.e. the ability of government to respond efficiently to crises and changes in the political environment, and a lack of confidence in the political institutions. ${ }^{13}$ On the one hand, it was argued that a parliamentary system would help to create the necessary conditions for the implementation of social and economic reforms, given the requirement that the government be supported by a majority in parliament at all times. On the other hand, it was argued that only under a presidential system would the population be able to directly choose its leaders and, as a consequence, to have actual influence on politics.

For approximately two months prior to the referendum, daily programs on TV and radio were broadcast to present and discuss the various arguments for and against each alternative. ${ }^{14}$ The parliamentary system received great support among legislators. A survey conducted in 1991 showed that $74 \%$ of the members of the congress were in favor of this alternative, although some parties with strong candidates in the upcoming elections ended up backing presidentialism. ${ }^{15}$

As shown in figure 1, the parliamentary regime started ahead in the polls. However, its advantage quickly faded as the campaigns on TV and radio began in mid February, after which one observes a marked shift in voting intentions towards presidentialism. Many political analysists attributed this change to an increase in voters' perception that a parliamentary system was, in fact, "government of congress". Indeed, this idea was heavily explored by the pro-presidentialism campaign, which had one TV advertisement asking viewers to "imagine what would happen if we put the country in the hands of the deputies...". ${ }^{16}$

The final result of the referendum is reported in table $1 .{ }^{17}$ The presidential system was the regime chosen by the population with $55 \%$ of the total votes. Note that a considerable fraction of individuals, approximately $20 \%$, cast a null or a blank vote. The turnout was around $75 \% .{ }^{18}$ Overall, the parliamentary regime received more support in the rich states of the southeast, such as Sao Paulo (34.5\%) and Rio de Janeiro (26.6\%), and less support in the poor states of the northeast, such as Piaui $(11.2 \%)$ and Paraiba (12.7\%).

\footnotetext{
${ }^{12}$ See Fleischer (1997) for more details.

${ }^{13}$ See Lamounier (1992) for a more detailed discussion of the main issues involved in the debate.

${ }^{14}$ The Brazilian electoral law obliges all TV and radio stations to broadcast campaign advertisements free of charge. The time on TV and radio was divided equally between supporters of each system.

${ }^{15}$ This survey was conducted by the Instituto de Estudos Economicos, Sociais e Politicos de Sao Paulo (IDESP), an independent research institute (Jornal da USP, 12/07/1992).

${ }^{16}$ Interestingly, the impeachment process of president Collor de Mello (Jan/1991-Oct/1992), which occurred in a relatively orderly fashion and counted with an active involvement of the population, seems to have had the actual effect of stregthening the voters' beliefs in their ability to hold the executive government accountable. This idea was also explored by the pro-presidentialism campaign, which used it to emphasize the fact that in a presidential system "you choose (the president), and you can remove".

${ }^{17}$ Figure A1 depicts the actual ballot used in the referendum. In addition to the question regarding the decision between "parliamentarism" and "presidentialism", voters were also asked to choose between "monarchy" and "republic" - a republican regime was ultimately adopted with $66 \%$ of the total votes.

${ }^{18}$ Voting is mandatory in Brazil.
} 
After the referendum, many explanations for the defeat of the parliamentary system were raised by analysts and politicians involved in the campaigns. The congress and the political parties were among the most blamed. According to a newspaper article, "supporters of parliamentarism agree that the image of the congress and the recent scandals involving the institution did not help. 'What you hear the most among the public is: not with this congress, not with this congress', laments Jose Serra [one of the leaders of the pro-parliamentarism campaign]" (Folha de Sao Paulo, 04/18/1993). Luis Inacio Lula da Silva, president of the country during 2002-2010 and, at that time, leader of the Labor Party, explained the result in the following terms: "The Brazilian congress is an institution that does not have the trust of the population." (Isto É, 04/28/1993). Almost fifteen years later, Fernando Henrique Cardoso, president during 1994-2002 and a strong supporter of a parliamentary system, admitted: "After my experience as president and in retrospect, I have many doubts. In reality, a parliamentary regime would have required a much stronger party system." (Agencia Brasil, 10/03/2008).

\subsection{Empirical Evidence: New Facts}

This subsection presents main stylized facts about the results of the Brazilian referendum of 1993. Our paper explores three sources of data. First, we use municipal level data on the outcomes of the referendum obtained from the Supreme Electoral Court of Brazil (Tribunal Superior Eleitoral [TSE]) and several regional Electoral Courts. Although part of the information was missing or unavailable, we were still able to recover data for 4, 178 municipalities, which amounts to $90 \%$ of the country's total population in $1993 .{ }^{19}$ Second, we use data from several opinion surveys conducted by the Datafolha, an independent research institute, from February to April 1993, containing detailed information about the voting intentions and the individual characteristics of a large number of subjects. ${ }^{20}$ Finally, data on the social and economic characteristics of Brazilian municipalities for the year 1991 were obtained from the Institute of Applied Economic Research (Instituto de Pesquisa Economica Aplicada [IPEA]). Table 2 reports basic descriptive statistics for the main variables used in the analysis.

Figure 2 plots the relationship between income per capita and the percentage of valid votes (i.e. excluding null and blank votes) cast for a parliamentary system, with each municipality represented as a circle proportional to its population. The graph shows the existence of a strong positive correlation between income per capita and the percentage of votes for a parliamentary system across Brazilian municipalities. Remarkably, the $R^{2}$ of this simple regression line is 0.56 . Observe that this relationship is not systematically driven by population size, although large municipalities do tend to be richer on average. Moreover, using micro data from an opinion poll conducted before the referendum, figure 3 shows that the intention to vote for a parliamentary system increases

\footnotetext{
${ }^{19}$ In Brazil, a municipality is defined as the smallest administrative subdivision to have its own democratically elected leadership, a mayor and a local assembly.

${ }^{20}$ These datasets were obtained from the Centro de Estudos de Opinião Pública, CESOP-UNICAMP.
} 
with household income. Thus, the evidence that the poor (rich) voted more for a presidential (parliamentary) system exists both at municipal and individual levels.

How robust are these results? At the municipal level, figures 4 and 5 show, respectively, that this evidence cannot be accounted for by income inequality (Gini coefficient) or voting for charismatic and populist leaders, as measured by the percentage of votes for Luis Inacio Lula da Silva (Labor Party) in 1994. ${ }^{21,22}$ Moreover, figure 6 shows that the stylized fact remains even after controlling for the party affiliation of mayors, which captures specific characteristics of the local politics.

Another possible explanation for this evidence could be attributed to the fact that poor individuals simply lacked knowledge about the referendum and, therefore, voted more for a presidential system merely because it represented the status quo. In order to investigate this possibility, we use information from an opinion survey which asked individuals to point out at least two differences between presidential and parliamentary regimes. Since the answers to this question were spontaneous, they allow us to identify a subgroup of people who can be considered to be "knowledgeable" enough about the referendum.

Out of 2, 607 subjects interviewed, 1, 059 (40.6\%) were able to correctly point out two or more differences between the two alternatives. ${ }^{23}$ Table 3 provides a summary of the voting intentions of subjects both in the full sample and in the subsample of "informed individuals". Surprisingly, voters with more knowledge about the referendum were comparatively more likely to vote for a presidential rather than a parliamentary system. Figure 7 then plots the voting intentions of informed and uninformed individuals across different classes of income. Observe that contrary to our initial expectation informed poor individuals were actually more likely to vote for a presidential system. ${ }^{24}$ We find, therefore, strong evidence that information about the referendum does not account for the stylized fact presented above. This is an interesting result in itself, considering that a lack of information among voters is often viewed as one of the main explanatory factors for the results of the 1993 referendum.

We further investigate the determinants of the constitutional preferences of voters in Brazil by performing a more detailed regression analysis. At the municipal level, table 4 presents the results of OLS regressions in which the percentage of valid votes cast for a parliamentary system is regressed on four main socio-economic variables, namely the logarithm of income per capita, the

\footnotetext{
${ }^{21}$ Lula was the most popular left-wing candidate in the two presidential elections of 1989 and 1994.

${ }^{22} \mathrm{An}$ interesting aspect of the Brazilian case is that the referendum took place in an environment without the presence of any particularly dominant political figure. In fact, the then current president, Itamar Franco, was just "filling the gap" between one government and another after the impeachment of Fernando Collor de Mello in 1993 and the candidate eventually elected in the presidential elections of 1994, Fernando Henrique Cardoso, was actually campaigning for a parliamentary system at the time of the referendum.

${ }^{23}$ Common answers to this question were: "the prime-minister is elected by the parliament", "the president is chosen by the population", "the congress is in charge" and "the power belongs to the president".

${ }^{24}$ Observe that the voting intention for the parliamentary system increases sharply among uninformed individuals as one moves from "less than 2 minimum wages" to "between 2 and 5 minimum wages". We conjecture that part of this large increase is driven by the fact that the very poor individuals may have had a harder time articulating answers to this relatively complex question. As a result, some of them may have ended up being classified as "uninformed", even though they were actually knowledgeable about the differences between the two systems. We, therefore, conjecture that the "true" voting intention line for uninformed individuals is flatter than the one depicted in figure 7, with their voting intentions being more or less constant across income categories.
} 
logarithm of population, the illiteracy rate and the Gini coefficient (income inequality), as well as other municipal characteristics. ${ }^{25}$ Following Ferraz and Finan $(2008,2011)$ and Litschig and Zamboni (2011), we also include the number of AM radio stations and a dummy for the presence of federal judges and prosecutors in each municipality. These authors have shown that the local media and judiciary play an important role in restraining corruption at the municipal level in Brazil, so we use these variables as proxies for the presence of local accountability institutions.

The sample is restricted to municipalities with fewer than 500, 000 citizens in order to exclude large outliers from the analysis All regressions include state fixed effects and we add dummies for the party affiliation of mayors in columns [2] and [4]. Overall, our estimates reveal a consistent pattern. The vote for a parliamentary system is always positively correlated with income per capita, which shows that the stylized fact presented above is robust to controlling for main municipal characteristics. Interestingly, the estimates for the number of AM radio stations and the presence of federal judges and prosecutors are positive and statistically significant across all specifications, suggesting that the local institutional environment is indeed relevant to the voting decision of citizens.

Next, at the individual level, we use survey data to analize the determinants of the intention to vote for a parliamentary system. The analysis takes into account several important explanatory variables, including household income, level of schooling, a measure of political ideology and the candidate voted for in the second round of the 1989 presidential elections, among other individual characteristics. ${ }^{26}$ We also control for whether the person believes that "the country would be better off if the military returned to power" and whether the level of his or her trust in congress is "very low".

Table 5 presents the estimation results. Column [1] reports estimates of a basic logit regression, showing that individual income has, in fact, a positive effect on the probability that a person votes for a parliamentary system. However, this result must be qualified by the fact that, as shown in column [2], both the magnitude and the significance of the estimated coefficients for each class of income drop considerably as municipal fixed effects are included in the regression, i.e. the importance of individual income decreases as we control for municipal characteristics. Therefore, we find evidence that the local economic and institutional environment is in fact relevant to determine the vote of citizens. It is also interesting to note that voters who do not trust the congress are less likely to vote for a parliamentary system, while individuals who define themselves as being more ideologically inclined towards the "right" tend to vote more for a presidential system.

Finally, we proceed to examine the main reasons behind the vote of Brazilian citizens in the

\footnotetext{
${ }^{25}$ The municipal characteristics considered in the analysis were the following: percentage of the population living in rural areas, population density (inhabitants $/ \mathrm{km}^{2}$ ), state capital dummy, distance to the state capital, percentage of abstention, percentage of null votes and percentage of votes cast for the PSDB (Fernando Henrique Cardoso) and the PT (Luis Inacio Lula da Silva) candidates in the 1994 presidential elections.

${ }^{26}$ The other individual characteristics included in the regressions were: gender, age, age squared, two dummy variables indicating whether the person knows the name of the president and the name of the state's governor and four dummy variables indicating whether the person is religious, favours abortion, favours the death penalty and serves in local communities.
} 
referendum. Figure 8 presents the results of a survey which asked individuals why they would not vote for a parliamentary system. The most frequent reason was that "citizens do not have the right to elect the leader and/or the members of the parliament are the ones who choose", which amounts to $28 \%$ of the subjects who reported not voting for this alternative. Furthermore, when the sample is restricted to the subgroup of informed voters, following the same criteria defined above, the percentage of individuals dissatisfied with the lack of direct elections increases to $41 \%$, while the fact that "the congress is corrupt" was pointed out by $12 \%$ as the main reason for rejecting this alternative.

As discussed before, a sense of dissatisfaction with congress and the political class in general was widespread among voters and played a crucial role in shaping the results of the referendum. We find abundant anecdotal evidence in this direction. As a reader of the newspaper Folha de Sao Paulo put it in a letter to the editor: "the referendum became a judgement of the congress". Interestingly, other topics frequently highlighted by previous research, such as political stability and size of government, were not nearly as prominent in public debates. That the trust in congress should affect the preferences over presidential and parliamentary systems seems intuitive, but the case of Brazil makes it clear that this element may be of first-order importance in the context of developing countries and recent democracies.

\subsection{Discussion}

Our analysis of the Brazilian referendum has established the existence of important and systematic differences in voting patterns across population groups. From a theoretical point of view, however, it is unclear why different people should have distinct preferences over the form of government and, in particular, why poor citizens should be more inclined towards a presidential system. While there have been several related studies in the recent political economy literature (Persson, Roland and Tabellini [1997, 2000] and Robinson and Torvik [2009]), none of them are able to fully account for the stylized facts presented above. In a sense, the evidence from Brazil is quite puzzling. For instance, many critics of presidentialism have pointed out that this system is inherently less stable and more prone to coups (Linz [1978] and Stepan and Skach [1993]), while Persson, Roland and Tabellini (2000) and Persson and Tabellini (2004) have argued that redistribution is larger under parliamentarism, which is especially beneficial to the poor population. From this perspective, and particularly after a long period of military dictatorship (1964-85), it would have been reasonable to expect that Brazilian voters, especially the poor, would have been more supportive of the parliamentary alternative, at least in order to decentralize power and restrict the authority of the central government. Why, then, do we observe exactly the opposite in the data? 


\section{Model}

This section proposes a model to study and compare the performance of presidential and parliamentary systems. The analysis focuses on the fundamental difference between these two regimes: while in presidential systems the executive leader is directly elected by voters and has a fixed term in office, in parliamentary systems the executive leader is appointed by the parliament and may be replaced if he receives a vote of no confidence. The model highlights the main trade-offs involved in the choice between these two forms of government. We use this framework to examine the factors that influence the preferences of different population groups between these alternatives. Our analysis concentrates primarily on explaining differences in voting behavior across constituencies, although some of its main insights could be used to explain part of the variation in individual voting behavior as well.

\subsection{Basic Setup}

We consider a moral hazard model with a single period. Following Acemoglu and Robinson (2001, 2006), the society is composed of two groups of voters, the "poor" and the "rich", indexed respectively by superscripts $p$ and $r$. The population is distributed over $n$ constituencies or localities, each consisting of a continuum of agents of the same group (i.e. citizens are either all poor or all rich) with measure $1 .{ }^{27}$ The number of poor and rich constituencies is given by $n^{p}$ and $n^{r}$, with $n^{p}>n^{r}$. We use the term "constituency" to broadly refer to a group of voters, distinguished by its geographical location, which serves as an electoral base for a representative. This structure applies naturally to the case where a majoritarian system ("winner-take-all") is in place, but also captures essential features of a proportional representation system with open party lists, given that candidates usually target specific groups of voters in a certain region. ${ }^{28,29}$

The utility function of each individual $i$ is given by:

$$
U_{i}=(1-\tau) y_{i}+\frac{1}{\alpha} \ell_{i}^{\alpha}-\frac{1}{2}\left(x-\theta_{i}\right)^{2},
$$

\footnotetext{
${ }^{27}$ Note that it would be possible to allow for income heterogeneity within each locality. Indeed, what is needed in the model is simply the existence of a median voter in each constituency as well as in the society as a whole. The homogeneity assumption is, therefore, imposed for simplicity and guarantees that there are only two types of constituencies in the society, one where everybody is poor and one where everybody is rich. The present framework does not yield many predictions about income inequality. However, this is not in contrast with the evidence that local inequality does not seem to have played a major role in the Brazilian referendum (see figure 4 above).

${ }^{28}$ The geographic concentration of votes for legislators is a well documented phenomenon in many countries that adopt multi-member district systems, e.g. Brazil (Fleischer [1976] and Ames [1995, 2001]), Colombia (Crisp and Ingall [2002] and Crisp and Desposato [2004]) and Japan (Hirano [2006]). Formally, Myerson (1993) shows that such systems encourage candidates to cater to narrow sub-constituencies ("favoured minorities"). The intuition for this result is that appealing to larger fractions of the electorate makes the candidate "vulnerable" to an opponent who is only targetting the minimum number of voters required to win elections.

${ }^{29}$ Ames (1995), in his analysis of the Brazilian electoral system, remarks that "legally, candidates may seek votes everywhere in their states, but in reality many concentrate their campaigns geographically, finding most of their support in one or more contiguous regions, regions popularly referred to as "electoral strongholds" (redutos eleitorais). Why concentrate on a specific area? For diverse reasons: the candidates' families have long held power in the region; a party leader sent them to the area; they appeal to its voters; they make a deal with a local political leader."
} 
where $\tau \in[0,1]$ is a common tax rate, $y_{i}$ is the income level, $\ell_{i} \geq 0$ represents the provision of a local public good in individual $i$ 's constituency (e.g. investment in education), $x \in \mathbb{R}$ is the position of a national public policy (e.g. a reform of the social security system) in the ideological space and $\theta_{i} \in\left\{\theta_{L}, \theta_{H}\right\}$ denotes the agent's preference over $x$, with $\theta_{H}-\theta_{L}=\Delta>0$. The parameter $\alpha$ is such that $0<\alpha<1$, which guarantees that the utility function is strictly increasing and concave in $\ell_{i}$.

We suppose that the members of each group are identical in all respects. The poor voters have income $y^{p}$ and preference $\theta^{p} \in\left\{\theta_{L}, \theta_{H}\right\}$, while the rich have income $y^{r}$, with $y^{r}>y^{p}$, and preference $\theta^{r} \in\left\{\theta_{L}, \theta_{H}\right\}$. The average income is normalized to unity, $\bar{y}=\frac{1}{n}\left(n^{p} y^{p}+n^{r} y^{r}\right)=1$, so that $y^{p}<1<y^{r}$.

The population is represented by $n+1$ elected officials, one executive leader, $e$, and $n$ legislators, $l \in\{1, \ldots, n\}$, elected in their respective constituencies. The utility function of each office-holder $j$ (executive leader or legislator) is given by:

$$
V_{j}=s_{j}-\frac{1}{2}\left(x-\theta_{j}\right)^{2}
$$

where $s_{j} \geq 0$ represents the amount of rents expropriated by office-holder $j$ and $\theta_{j} \in\left\{\theta_{L}, \theta_{H}\right\}$ denotes his preference parameter.

The vector of policies is given by $\left(x,\left(\tau, \varphi, s_{e}\right),\left\{\left(\ell_{i}, s_{i}\right)\right\}_{i=1}^{n}\right)$ and consists of a set of variables determined through the political process. The public policy $x$ and the budget policy $\left(\tau, \varphi, s_{e}\right)$ are decided at the national level and must satisfy the aggregate budget constraint:

$$
n \varphi+s_{e} \leq n \tau
$$

where $\varphi$ represents a lump-sum transfer common to all constituencies and $s_{e}$ is the amount of rents expropriated by the executive leader. ${ }^{30}$ At the local level, transfers are allocated between the provision of local public goods, $\ell_{i}$, and political rents to the local legislator, $s_{i}$, subject to the following budget constraint: ${ }^{31}$

$$
\ell_{i}+s_{i} \leq \varphi
$$

We assume that the politicians cannot commit to policy platforms prior to elections. This creates a moral hazard problem in that once in office they will have an incentive to implement the best policies for themselves. As in Persson, Roland and Tabellini (1997, 2000), voters are able to discipline their representatives only "retrospectively" by threatening not to reelect them at the end of the period. The executive leader and the legislators are assumed to receive, respectively, exogenous rewards $\omega_{E} \geq 0$ and $\omega_{L} \geq 0$ when reelected. These parameters capture, in a reduced-

\footnotetext{
${ }^{30}$ The assumption that transfers are common across constituencies can be interpreted as capturing the restrictions imposed by a "federalist pact" on how resources can be distributed among voters. Note that our framework still allows for redistribution towards the poor, since taxation is proportional to income. If transfers were allowed to be targeted by groups, then the rich would always receive zero resources in equilibrium. The model could be extended to incorporate some degree of "targeting", in addition to the lump-sum transfers, without changing our main insights.

${ }^{31}$ With a slight abuse of notation, we use the subscript $i$ to refer both to constituencies and their members.
} 
form fashion, the benefits associated with continuing in office and remaining popular with voters, which include "ego rents", legacy motives and future rents.

\subsection{Preference Structure}

We assume that the preference of the poor citizens is always given by $\theta^{p}=\theta_{L}$. At the beginning of the period, the rich voters' type is realized with $\operatorname{Pr}\left(\theta^{r}=\theta_{L}\right)=\rho$, where the parameter $\rho$ can be interpreted as a measure of social homogeneity. After that, the government is formed with all the office-holders aligned with the preference of their respective constituencies: the executive leader has the same type as the median (poor) voter, $\theta_{e}=\theta_{L}$, and all the legislators have the same preference as their constituents, i.e. the legislators representing the poor have type $\theta_{L}$, while those representing the rich have type $\theta^{r}$.

A preference shock then occurs with probability $\xi \in(0,1)$ and may change the preferences of all the office-holders. Each politician, executive leader or legislator, remains aligned with their constituencies with probability $\pi \in(0,1)$, where the parameter $\pi$ can be interpreted as a measure of the quality of political representation in the society. After the occurrence of the shock, there are four possible scenarios relevant to the analysis, two in which the preferences of the executive leader and the median legislator are the same, $\theta_{e}=\theta_{l^{m}}$, and two in which they are different, $\theta_{e} \neq \theta_{l^{m}}$. We suppose that the office-holders' new types are drawn independently from each other and that the preferences of the executive leader and the median legislator are observed by everyone. Note that, since all shocks are independent, nothing would change in the model if we allowed for a change in the voters' preferences, provided that we have $\operatorname{Pr}\left(\theta^{p}=\theta^{r}\right)=\rho$ and that, after the shock, the office-holders remain aligned with their constituencies with probability $\pi$.

This structure is intended to capture an environment in which the relevant policy issue (e.g. international affairs or fiscal policy) becomes known only after the government is formed, due to uncertainty about the future state of the world. The preference shock, thus, reflects the possibility of changes in current economic and political conditions combined with the fact that elected officials may not be aligned with the interests of their constituencies in every policy dimmension. Furthermore, the assumption that the preferences of the executive leader and the median legislator are observed after the shock captures the idea that their stance on some main political issues are known from public speeches, debates and interviews, as well as from their past career and background.

\subsection{Political Structure}

The government is divided into two branches, the executive and the legislative, each responsible for a distinct but complementary role in the policy-making process. The legislative assembly is composed of $n$ members elected in their constituencies, while the executive is composed of a single member whose appointment process depends on the form of government. Specifically, in a presidential system the president is elected and held accountable directly by the voters, while in a 
parliamentary system the prime minister is appointed and held accountable by the members of the parliament, who can remove him through a vote of no confidence.

After the uncertainty over preferences is resolved, the executive leader is called upon to make a proposal $\widetilde{\mathbf{q}}=\left(\widetilde{x},\left(\widetilde{\tau}, \widetilde{\varphi}, \widetilde{s}_{e}\right)\right)$, which consists of a public policy $\widetilde{x}$ and a budget policy $\left(\widetilde{\tau}, \widetilde{\varphi}, \widetilde{s}_{e}\right)$. The proposal is then submitted to the legislature, where representatives vote separately on $\widetilde{x}$ and $\left(\widetilde{\tau}, \widetilde{\varphi}, \widetilde{s}_{e}\right)$. This structure captures both the de jure and the de facto agenda-setting powers held by the executive leader under each regime. ${ }^{32}$ Furthermore, the assumption of a separate vote on each issue is consistent with the common practice in most legislatures, where distinct bills, such as a budget proposal and a reform of the health care system, are discussed and voted on independently.

The legislative process differs across the two systems. In the presidential regime, each element of the proposal is approved if supported by a majority of legislators. Otherwise, a default public policy $x^{o}=\frac{\theta_{L}+\theta_{H}}{2}$ is implemented when $\widetilde{x}$ is rejected, while a default budget $\left(\tau^{o}, \varphi^{o}, s_{e}^{o}\right)$ is adopted when $\left(\widetilde{\tau}, \widetilde{\varphi}, \widetilde{s}_{e}\right)$ is rejected. In the parliamentary regime, on the other hand, after observing the proposal, the members of the parliament vote on a motion of no confidence on the executive. Intuitively, in this case, the policy vector $\widetilde{\mathbf{q}}$ can be interpreted as the leader's "program of government". If the vote of no confidence is rejected, the prime minister remains in office and the proposal is implemented. Otherwise, a new executive leader $e^{\prime}$ is appointed and given the chance to make another policy proposal $\widetilde{\mathbf{q}}^{\prime}$, which is then voted on against the status quo, as in a presidential system.

We assume that the new prime minister is chosen among a pool of candidates from outside the parliament and that the majority of legislators is able to select an agent with the same preference as their own. ${ }^{33}$ As we shall discuss below, the cases in which the vote of no confidence can make a difference are those where the preferences of the executive leader and the median legislator are misaligned, $\theta_{e} \neq \theta_{l^{m}}$. The new prime minister is not subject to a confidence procedure, but is held accountable by legislators who decide, by majority rule, whether to reappoint him or not at the end of the period. ${ }^{34}$ The assumption of a single vote of no confidence is in line with the fact that many parliamentary democracies impose a limit on the number of censure motions that can be proposed in a given period. It also captures the idea that most political issues require that a decision be reached in a timely manner in order to avert an imminent crisis or so that the policy itself does not lose its effectiveness, in which case a vote against the government would be equivalent

\footnotetext{
${ }^{32}$ Indeed, the majority of the bills in parliamentary systems are initiated by the cabinet, while many presidential democracies provide substantial agenda-setting powers to their executive governments (Mainwaring and Shugart [1997]). Even in the United States, where the president has only limited authority to propose bills, the executive often plays a fundamental role in shaping legislation. An example of this can be found in the conduct of the Obama administration during the negotiations over the health care reform. According to an article in the New York Times, "in pursuing his proposed overhaul of the health care system, President Obama has consistently presented himself as aloof from the legislative fray, merely offering broad principles. (...) Behind the scenes, however, Mr. Obama and his advisers have been quite active, sometimes negotiating deals with a degree of cold-eyed political realism potentially at odds with the president's rhetoric." (New York Times, 08/13/2009).

${ }^{33}$ The assumption that the new prime minister is selected from outside the parliament is in line with the notion of a caretaker technocratic government taking office after the fall of the cabinet. Recent examples of this include the governments lead by Lucas Papademos in Greece and Mario Monti in Italy. From a formal perspective, we impose this assumption in order to keep a symmetry between our models of presidentialism and parliamentarism.

${ }^{34}$ Allowing the parliament to replace the government for a finite number of times would not change any of the results of the model.
} 
to maintaining the status quo.

After the legislative process is completed, a vector of policies $\left(x,\left(\tau, \varphi, s_{e}\right)\right)$ is adopted under both systems and each legislator decides how to allocate the transfers received by his constituency between the provision of local public goods, $\ell_{i}$, and expropriation of rents, $s_{i}$. Voters observe the policies $\left(x,\left(\tau, \varphi, s_{e}\right)\right)$ and $\left(\ell_{i}, s_{i}\right)$ as they are implemented. At the end of the period, they decide, by majority rule, whether to reelect or not their representatives and the president based on their behaviour during the period.

A strategy for citizens is a "retrospective voting rule", which specifies the conditions under which an incumbent will receive their electoral support at the time of elections. We impose that, in equilibrium, any voting rule must be credible (i.e. satisfy subgame perfection) in the sense that voters do not want to reoptimize their strategies in later stages of the game, as additional information becomes available. It is also assumed that a prime minister who receives the confidence of the parliament is always reappointed, while the "second" prime minister is held accountable by the legislators and depends on their political support at the end of the period in order to remain in office (i.e. the legislators decide whether to reelect him or not). Intuitively, the new prime minister has his proposal voted on only against the status quo and, as a consequence, does not receive the "full" confidence of the parliament.

\subsection{Accountability Institutions}

Finally, we describe the role of the accountability institutions in our framework. First, it is assumed that when a legislator $i$ is not reelected, voters are able to recover the expropriated resources, $s_{i}$, with probability $\lambda_{i} \in(0,1)$, where the parameter $\lambda_{i}$ can be interpreted as a measure of the quality of local institutions. We suppose that the level of institutional protection in poor and rich constituencies is distinct, with $\lambda^{r}>\lambda^{p}$. This heterogeneity generates a variation in the ability of voters to constraint expropriation at the local level, so that corruption constitutes a greater burden to the poor than to the rich. This feature of the model is in accordance with recent empirical evidence by Ferraz and Finan $(2008,2011)$, who emphasize the role of the local media in restraining corruption in Brazilian municipalities. Similarly, we assume that when the executive leader is not reappointed, the expropriated resources, $s_{e}$, are recovered with probability $\bar{\lambda} \in(0,1)$, where the parameter $\bar{\lambda}$ captures the quality of national institutions (e.g. federal prosecutors and the national media) which provide common protection to the population as a whole. Observe that the assumption that both national and local institutions act only when an office-holder is ousted from power is in accordance with the fact that a thorough investigation of a corruption scandal may be hindered either because the politician while in office is in a privileged position to manipulate evidence or due to constitutional immunities that are often granted to office-holders. In any case, all qualitative results of the model would remain unchanged as long as we assumed that the probability with which a politician is prosecuted is higher when he is not in office. 


\subsection{Timing}

To summarize, the timing of the events under the presidential system is as follows:

(1) The preference shock occurs with probability $\xi$, determining the preferences of the executive leader and the median legislator, $\theta_{e}$ and $\theta_{l^{m}}$.

(2) The executive leader makes a policy proposal $\widetilde{\mathbf{q}}=\left(\widetilde{x},\left(\widetilde{\tau}, \widetilde{\varphi}, \widetilde{s}_{e}\right)\right)$.

(3) The congress votes separately on $\widetilde{x}$ and $\left(\widetilde{\tau}, \widetilde{\varphi}, \widetilde{s}_{e}\right)$. Each element of the proposal is approved if supported by a majority in congress. Otherwise, a default public policy $x^{o}=\frac{\theta_{L}+\theta_{H}}{2}$ is implemented when $\widetilde{x}$ is rejected, while a default budget $\left(\tau^{o}, \varphi^{o}, s_{e}^{o}\right)$ is implemented when $\left(\widetilde{\tau}, \widetilde{\varphi}, \widetilde{s}_{e}\right)$ is rejected.

(4) Each constituency $i$ receives a transfer $\varphi$ and the local legislator decides how to allocate it between local public goods, $\ell_{i}$, and political rents, $s_{i}$.

(5) Elections are held and voters decide whether to reelect their representatives and the president.

The timing of the events under a parliamentary system is similar, except that stages (3) and (5) are replaced by:

$\left(3^{\prime}\right)$ The parliament votes on a motion of no confidence on the executive. If the vote of no confidence is rejected, the prime minister remains in office and the proposal is implemented. Otherwise, a new executive leader $e^{\prime}$ is appointed and given the chance to make another proposal $\widetilde{\mathbf{q}}^{\prime}$, which is then voted on against the status quo.

$\left(5^{\prime}\right)$ Elections are held and voters decide whether to reelect their representatives. A prime minister who receives the confidence of the parliament is automatically reappointed, while the "second" prime minister depends on the support of the legislators to stay in office (i.e. the legislators decide whether to reelect him or not at the end of the period).

\section{Equilibrium}

This section solves for a subgame-perfect Nash equilibrium of the model. We proceed by backward induction, starting in subsection 4.1 with an analysis of the final subgame, which is common to both systems of government. The presidential regime is, then, discussed in subsection 4.2 and the parliamentary regime in subsection 4.3 . 


\subsection{Local Politics}

After the vector of policies $\mathbf{q}=\left(x,\left(\tau, \varphi, s_{e}\right)\right)$ is approved and observed by all, each constituency receives a transfer $\varphi$ and the local legislator decides how to allocate it between the provision of local public goods and the expropriation of rents. When the legislator decides not to pursue reelection, his optimal strategy is to expropriate all the resources, in which case he obtains $\left(1-\lambda_{i}\right) \varphi$ in expected utility. Therefore, given the amount of transfers $\varphi$ received, voters in each constituency formulate their reelection rules so as to minimize the amount of rents expropriated by legislator $i$ according to the following problem:

$$
\min _{s_{i} \geq 0} s_{i}
$$

subject to:

$$
\begin{cases}\ell_{i}+s_{i} \leq \varphi & \left(B C_{i}\right) \\ s_{i}+\beta \omega_{L} \geq\left(1-\lambda_{i}\right) \varphi & \left(I C_{i}\right)\end{cases}
$$

where $\beta \in(0,1)$ is the discount factor. The incentive compatibility constraint $\left(I C_{i}\right)$ guarantees that the legislator prefers to pursue reelection rather than to implement his outside option. At the optimum, both the budget and the incentive constraint must bind, so that:

$$
s_{i}(\varphi)=\max \left\{\left(1-\lambda_{i}\right) \varphi-\beta \omega_{L}, 0\right\}
$$

and

$$
\ell_{i}(\varphi)=\varphi-\max \left\{\left(1-\lambda_{i}\right) \varphi-\beta \omega_{L}, 0\right\}
$$

Intuitively, equation (7) determines the minimum amount of local public goods demanded by voters in order to reelect their representatives. In equilibrium, policies are always adopted according to these expressions and all the legislators are reappointed.

Observe that political rents are equal to zero when:

$$
\varphi \leq \frac{\beta \omega_{L}}{1-\lambda_{i}}
$$

In order to simplify the analysis, and to avoid uninteresting cases, we assume that the status quo transfer is such that $\varphi^{o}>\frac{\beta \omega_{L}}{1-\lambda^{p}}$, which guarantees that the amount of rents extracted by any legislator representing the poor is always strictly positive. Observe that this condition can be reexpressed as $\omega_{L}<\frac{1}{\beta}\left(1-\lambda^{p}\right) \varphi^{o}$, which requires that the reelection rewards of legislators are not too high.

Assumption 1. $\omega_{L}<\frac{1}{\beta}\left(1-\lambda^{p}\right) \varphi^{o}$.

An important feature of the present framework is that legislators are held accountable for their behavior at the local level, despite the fact that they also perform other actions prior to this stage. Note that any subgame perfuct equilibrium requires that, once transfers $\varphi$ are observed, the optimal reelection strategy of voters must be given by the solution to problem (5) above. This 
renders any other voting rule non-credible, as voters would always have an incentive to re-optimize their strategies after transfers become known. The idea that representatives are held accountable for their local behaviour is particularly reasonable in an environment where citizens do not have access to the individual voting record of their representatives, either due to a low degree of political awareness or a lack of congressional transparency. ${ }^{35}$

\subsection{Presidential System}

This subsection characterizes the policies implemented under a presidential system of government, taking as given that the rents expropriated by legislators and the provision of local public goods are determined, respectively, by equations (6) and (7) derived above.

\subsubsection{Legislative Process}

Suppose that a proposal $\widetilde{\mathbf{q}}=\left(\widetilde{x},\left(\widetilde{\tau}, \widetilde{\varphi}, \widetilde{s}_{e}\right)\right)$ has been submitted to congress. Observe that it is dominant for each legislator $l$ to vote in favour of the budget proposal $\left(\widetilde{\tau}, \widetilde{\varphi}, \widetilde{s}_{e}\right)$ if, and only if, $s_{l}(\widetilde{\varphi}) \geq s_{l}\left(\varphi^{o}\right)$. Under assumption 1 , we have that $s^{p}\left(\varphi^{o}\right)>0$, so that the amount of rents extracted by the legislators representing the poor is positive and strictly increasing in transfers. Thus, the condition for the approval of $\left(\widetilde{\tau}, \widetilde{\varphi}, \widetilde{s}_{e}\right)$ is given by:

$$
\widetilde{\varphi} \geq \varphi^{o}
$$

Similarly, the public policy $\widetilde{x}$ is approved in congress if, and only if, a majority of legislators prefers it to the status quo, $x^{o}=\frac{\theta_{L}+\theta_{H}}{2}$, which requires that:

$$
-\frac{1}{2}\left(\widetilde{x}-\theta_{l^{m}}\right)^{2} \geq-\frac{\Delta^{2}}{8}
$$

where $\theta_{l^{m}}$ denotes the preference of the median legislator $l^{m}$. We refer to these conditions as the "approval constraints".

\subsubsection{Incentive Constraint on the President}

After the occurrence of the preference shock, the executive leader is called upon to make a proposal $\widetilde{\mathbf{q}}$. The president is held accountable by the voters, but always has the option to give up reelection and propose a policy that maximizes his utility subject to the budget constraint and the conditions for congressional approval, $\left(A P_{1}\right)$ and $\left(A P_{2}\right)$. In this case, the president sets $\tau=1$ and $\varphi=\varphi^{\circ}$,

\footnotetext{
${ }^{35}$ These conditions are especially likely to hold in new democracies and developing countries. According to Ames (1995), "Brazilian citizens exert pressure for pork-barrel programs, but on broader issues they have little control over their representatives. This should come as no surprise, because no one observing a Brazilian election would feel confident that many voters know anything at all about the positions of their deputies". Moreover, even in the case of highly developed countries such as Japan, several studies have documented that a considerable fraction of the electorate vote exclusively on the basis of local and parochial interests (Richardson [1997]).
} 
which gives him $n(1-\bar{\lambda})\left(1-\varphi^{o}\right)$ in expected utility. Furthermore, when $\theta_{e}=\theta_{l^{m}}$, he is able to approve his preferred policy $x=\theta_{e}$, while when $\theta_{e} \neq \theta_{l^{m}}$ he is able to obtain at most $x^{o}=\frac{\theta_{L}+\theta_{H}}{2}$, due to the opposition of congress.

Therefore, in order to induce the president to pursue reelection, voters must satisfy the following incentive compatibility constraint:

$$
s_{e}-\frac{1}{2}\left(x-\theta_{e}\right)^{2}+\beta \omega_{E} \geq n(1-\bar{\lambda})\left(1-\varphi^{o}\right)-1_{\left\{\theta_{e} \neq \theta_{\left.l^{m}\right\}}\right.} \frac{\Delta^{2}}{8},
$$

where $1_{\left\{\theta_{e} \neq \theta_{l} m\right\}}$ is an indicator function that equals one when the preferences of the president and the median legislator are misaligned. In order to focus on the interesting case, we assume that $\kappa \equiv n(1-\bar{\lambda})\left(1-\varphi^{o}\right)-\beta \omega_{E}>0$, which guarantees that the amount of rents extracted by the executive leader is always strictly positive, $s_{e}>0$. Intuitively, this condition requires that the reelection rewards of the president are not too high.

Assumption 2. $\omega_{E}<\frac{n}{\beta}(1-\bar{\lambda})\left(1-\varphi^{o}\right)$.

\subsubsection{Equilibrium}

The poor voters constitute the majority of the population and are, therefore, decisive for the reappointment of the president. Thus, given the realization of the politicians' preferences, $\theta_{e}$ and $\theta_{l^{m}}$, they formulate their reelection strategies so as to maximize their utilities according to the following problem:

$$
\max _{x \in \mathbb{R},(\tau, \varphi) \in[0,1]^{2}}(1-\tau) y^{p}+\frac{1}{\alpha} \ell^{p}(\varphi)^{\alpha}-\frac{1}{2}\left(x-\theta_{L}\right)^{2}
$$

subject to

$$
\left\{\begin{array}{l}
n \varphi+s_{e} \leq n \tau \\
\left(I C_{e}\right),\left(A P_{1}\right),\left(A P_{2}\right)
\end{array} \quad(B C)\right.
$$

The main properties of the equilibrium are summarized in the next lemma. ${ }^{36}$

Lemma 1. The equilibrium under a presidential system is characterized by the following properties:

$i$. The tax rate may be lower than one, $\tau \leq 1$.

ii. The size of transfers is (weakly) increasing in the quality of institutions available to the poor, $\lambda^{p}$, and (weakly) decreasing in the poor voters' income, $y^{p}$. Furthermore, transfers are always such that $\varphi \leq 1-\frac{\kappa}{n}$.

iii. The amount of rents extracted by the executive leader is such that $s_{e} \geq \kappa$, with strict inequality when $\theta_{e}=\theta_{H}$.

\footnotetext{
${ }^{36}$ All proofs for this paper are collected in Appendix A (NOT FOR PUBLICATION).
} 
$i v$. For any type of median legislator, the distance $\left|x-\theta_{L}\right|$ is largest when the president is misaligned with the preference of the poor population, i.e. $\theta_{e}=\theta_{H}$.

In a presidential system, the existence of direct elections for the executive branch provides an institutional mechanism for the poor to influence policies according to their interests. In particular, the size of the taxes and transfers "demanded" by the population depends both on the cost of taxation and on how effectively the resources can be converted into local public goods. Formally, the optimal transfers are such that:

$$
\varphi=\max \left\{\varphi^{o}, \widehat{\varphi}\right\}
$$

where (assuming that the constraint $\tau \leq 1$ is not binding) $\widehat{\varphi}$ is implicitly determined by:

$$
\underbrace{\ell^{p}(\widehat{\varphi})^{\alpha-1} \lambda^{p}}_{\text {marg. utility of transfers }}=\underbrace{y^{p}}_{\text {marg. cost of taxation }}
$$

Therefore, in equilibrium, transfers are: $(i)$ (weakly) increasing in the quality of institutions available to the poor, $\lambda^{p}$, which reduces the expropriation of rents at the local level, and (ii) (weakly) decreasing in the poor voters' income, $y^{p}$, which raises the cost of taxation for the members of this group. 37

An important drawback associated with direct elections is that they impose a limit on the frequency with which voters are able to check the government, so that a misaligned president, $\theta_{e}=\theta_{H}$, can never be removed from office before the end of his term. The executive leader is, therefore, in a strong position to push for outcomes that are favourable to himself and, as a consequence, is able to extract more rents and to distort the public policy towards his preferred position.

Observe that, from the incentive compatibility constraint, it follows that political rents are given by:

$$
s_{e}=\kappa+\Psi(\widetilde{x} ; \boldsymbol{\theta})
$$

where $\Psi(\widetilde{x} ; \boldsymbol{\theta})=\frac{1}{2}\left(\widetilde{x}-\theta_{e}\right)^{2}-1_{\left\{\theta_{e} \neq \theta_{l^{m}}\right\}} \frac{\Delta^{2}}{8}$ is the amount of rents that must be paid above $\kappa$ in order to incentivize the president to propose a public policy $\widetilde{x}$. When the executive leader is aligned with voters, $\theta_{e}=\theta_{L}$, the equilibrium entails $x=\theta_{L}$ when $\theta_{l^{m}}=\theta_{L}$ and $x=\frac{\theta_{H}+\theta_{L}}{2}$ when $\theta_{l^{m}}=\theta_{H}$, so that $\Psi(x ; \boldsymbol{\theta})=0$ in both cases. A misaligned executive leader, on the other hand, must be paid additional rents in order to propose a policy that is closer to the voters' preference. The size of these rents is given by:

$$
\Psi(\widetilde{x} ; \boldsymbol{\theta})=\frac{1}{2}\left(\widetilde{x}-\theta_{H}\right)^{2}-1_{\left\{\theta_{e} \neq \theta_{l^{m}}\right\}} \frac{\Delta^{2}}{8}
$$

At the optimum, voters choose $\widetilde{x}$ in order to equalize the marginal benefit of reducing the distance $\left|\widetilde{x}-\theta_{L}\right|$ and the marginal cost of having to provide extra rents for the president. Therefore, $s_{e} \geq \kappa$, with strict inequality when $\theta_{e} \neq \theta_{L}$, and from the budget constraint it folows that $\varphi \leq 1-\frac{\kappa}{n}$.

\footnotetext{
${ }^{37}$ Note that these results are "weak" given the possibility that $\widehat{\varphi}<\varphi^{o}$.
} 


\subsection{Parliamentary System}

We now proceed to characterize the vector of policies implemented under a parliamentary system of government. As before, the rents expropriated by legislators and the provision of local public goods are determined, respectively, by equations (6) and (7) derived above.

\subsubsection{Legislative Process}

Suppose that a program of government $\widetilde{\mathbf{q}}=\left(\widetilde{x},\left(\widetilde{\tau}, \widetilde{\varphi}, \widetilde{s}_{e}\right)\right)$ has been proposed by the prime minister. The members of the parliament vote on a motion of no confidence on the executive. If the vote of no confidence is rejected, the prime minister remains in office and the proposal is implemented, in which case each legislator obtains:

$$
V_{l}=s_{l}(\widetilde{\varphi})-\frac{1}{2}\left(\widetilde{x}-\theta_{l}\right)^{2}
$$

If, on the other hand, the motion of no confidence is approved, a new prime-minister $e^{\prime}$ is selected, with a preference equal to that of the median legislator, $\theta_{e^{\prime}}=\theta_{l^{m}}$, and given the chance to make another proposal $\widetilde{\mathbf{q}}^{\prime}$, which is then voted on against the status quo. The new executive leader is not subjected to the confidence of the parliament, but legislators are able to hold him accountable by threatening not to reappoint him at the end of the term. Specifically, the median legislator formulates his voting strategy according to the following problem:

$$
\begin{array}{r}
\max _{x \in \mathbb{R},}(\tau, \varphi) \in[0,1]^{2} \\
\text { s.t. }\left\{\begin{array}{l}
n \varphi+s_{l^{\prime}} \leq n \tau \\
n \varphi \frac{1}{2}\left(x-\theta_{l^{m}}\right)^{2} \\
s_{e^{\prime}}-\frac{1}{2}\left(x-\theta_{e^{\prime}}\right)^{2} \geq \kappa
\end{array} \quad(B C)\right.
\end{array}
$$

where $\kappa \equiv n(1-\bar{\lambda})\left(1-\varphi^{o}\right)-\beta \omega_{E}>0$ under assumption 2. As before, the incentive compatibility constraint $\left(I C_{e^{\prime}}\right)$ guarantees that the executive leader prefers to pursue reelection rather than to implement his outside option. Observe that there is no conflict associated with the public policy decision in this case, since both the median legislator and the "second" prime-minister have identical preferences.

The optimal solution to this problem involves setting $x=\theta_{l^{m}}$ and $s_{e^{\prime}}=\kappa$. Moreover, since the amount of rents expropriated by legislators is increasing in transfers, and strictly so for any legislator representing the poor (under assumption 1), the reappointment rule specifies $\tau=1$ and

$\varphi=1-\frac{\kappa}{n}$, i.e. taxes and transfers are set as high as possible. Therefore, the utility obtained by the median legislator after a vote of no confidence is:

$$
V_{l^{m}}=s_{l^{m}}\left(1-\frac{\kappa}{n}\right)
$$




\subsubsection{Confidence Requirement}

From equations (12) and (14), it follows that it is dominant for the median legislator to support the government in a vote of confidence if, and only if, the initial proposal $\widetilde{\mathbf{q}}$ satisfies the following condition:

$$
s_{l^{m}}(\widetilde{\varphi})-\frac{1}{2}\left(\widetilde{x}-\theta_{l^{m}}\right)^{2} \geq s_{l^{m}}\left(1-\frac{\kappa}{n}\right),
$$

where we refer to this condition as the "confidence requirement" constraint.

\subsubsection{Equilibrium}

Proceeding by backward induction, after the occurrence of the preference shock, the prime minister is called upon to make a proposal $\widetilde{\mathbf{q}}$ subject to the confidence requirement of the parliament. Formally, he proposes a policy that maximizes his utility according to the following problem:

$$
\begin{aligned}
& \max _{\widetilde{x} \in \mathbb{R},(\widetilde{\tau}, \widetilde{\varphi}) \in[0,1]^{2}} \widetilde{s}_{e}-\frac{1}{2}\left(\widetilde{x}-\theta_{e}\right)^{2} \\
& \text { s.t. }\left\{\begin{array}{l}
n \widetilde{\varphi}+\widetilde{s}_{e} \leq n \widetilde{\tau} \quad(B C) \\
(C R)
\end{array}\right.
\end{aligned}
$$

When the preferences of the prime-minister and the median legislator are the same, $\theta_{e}=\theta_{l^{m}}$, the optimal solution is given by: $x=\theta_{l^{m}}, s_{e}=\kappa, \tau=1$ and $\varphi=1-\frac{\kappa}{n}$. That is, the executive leader simply announces exactly the same policies that would have been proposed by his successor had he been defeated in the vote of no confidence. When, on the other hand, the prime minister is not aligned with the parliament, $\theta_{e} \neq \theta_{l^{m}}$, the optimal solution involves a distortion of the reform away from the median legislator's preference in exchange for an increase in the size of transfers to constituencies.

Observe that the "relevant" median legislator for this problem is always a representative of the poor. Indeed, the executive leader prefers to seek the support of legislators from this group, since they are "cheaper" to buy. Intuitively, a poor representative is able to extract more rents out of the same amount of tranfers and, therefore, requires fewer resources in order to support the government whenever $x \neq \theta_{l^{m}}$. Furthermore, by obtaining the suport of the median poor legislator, the primeminister automatically guarantees the votes of all other poor representatives. This is because the parliament members with median preference are always the ones whose support is most difficult to obtain, given that they hold control over the appointment of the following government and, as a result, have better outside options.

The main properties of the equilibrium are summarized in the next lemma.

Lemma 2. The equilibrium under a parliamentary system is characterized by the following properties:

$i$. The tax rate is always equal to one, $\tau=1$. 
ii. The size of transfers is such that $\varphi \geq 1-\frac{\kappa}{n}$, with strict inequality when $\theta_{e} \neq \theta_{l^{m}}$.

iii. The amount of rents extracted by the executive leader is such that $s_{e} \leq \kappa$, with strict inequality when $\theta_{e} \neq \theta_{l^{m}}$.

$i v$. When the executive leader is of type $\theta_{e}=\theta_{H}$, the distance $\left|x-\theta_{L}\right|$ is smallest when the median legislator is aligned with the preference of the poor population, $\theta_{l^{m}}=\theta_{L}$.

In a parliamentary system, the ability to check the executive is delegated to legislators, who hold the prime minister accountable through the confidence procedure. This implies that the members of the parliament are in a strong position to push for higher transfers, which expands their expropriation opportunities at the local level. The executive leader, in turn, sets the tax rate at its maximum, both in order to satisfy the demands of legislators and to raise his own rents.

At the same time, the vote of no confidence adds flexibility to the parliamentary system by providing an institutional mechanism to replace the prime minister before the end of his term. A misaligned leader, $\theta_{e} \neq \theta_{l^{m}}$, must satisfy the demands of the parliament to stay in office and is, therefore, forced to accept a reduction in rents whenever the public policy is to be distorted away from the median legislator's preference. Formally, the confidence requirement imposes that:

$$
s^{p}(\widetilde{\varphi})=s^{p}\left(1-\frac{\kappa}{n}\right)+\frac{1}{2}\left(\widetilde{x}-\theta_{l^{m}}\right)^{2},
$$

where $s^{p}(\cdot)$ is the amount of rents obtained by a legislator representing a poor district. Observe that when $\widetilde{x} \neq \theta_{l^{m}}$, we must have that $\widetilde{\varphi}>1-\frac{\kappa}{n}$ and $\widetilde{s}_{e}<\kappa$.

Overall, the confidence procedure strengthens the bargaining power of the parliament considerably. Thus, an important requirement for the parliamentary system to perform in accordance with the interests of voters is that the legislative be expected to represent the preferences of the population with sufficiently high likelihood. In particular, observe that the vote of no confidence works in favor of the poor citizens whenever $\theta_{e}=\theta_{H}$ and $\theta_{l^{m}}=\theta_{L}$. In fact, this is the only case where the confidence procedure may be effectively used to protect their interests.

\section{Main Comparative Results}

This section presents the main comparative results of our analysis. The first proposition compares the size of taxes, transfers and political rents under both systems of government.

Proposition 1. From Lemmas 1 and 2, it follows that:

i. The tax rate is higher under parliamentary systems:

$$
\tau^{\text {pres }} \leq \tau^{\text {parl }}=1
$$


ii. The size of transfers and the provision of local public goods are higher under parliamentary systems:

$$
\varphi^{\text {pres }} \leq \varphi^{\text {parl }} \quad \text { and } \quad \ell_{i}^{\text {pres }} \leq \ell_{i}^{\text {parl }},
$$

with $\mathbb{E}\left(\varphi^{\text {pres }}\right)<\mathbb{E}\left(\varphi^{\text {parl }}\right)$ and $\mathbb{E}\left(\ell_{i}^{\text {pres }}\right)<\mathbb{E}\left(\ell_{i}^{\text {parl }}\right)$.

iii. The expected amount of rents extracted by legislators is larger under parliamentary systems:

$$
\mathbb{E}\left(s_{l}^{\text {pres }}\right) \leq \mathbb{E}\left(s_{l}^{\text {parl }}\right)
$$

with strict inequality if the legislator represents a poor constituency, while the expected amount of rents obtained by the executive leader is larger under presidential systems:

$$
\mathbb{E}\left(s_{e}^{\text {pres }}\right)>\mathbb{E}\left(s_{e}^{\text {parl }}\right)
$$

Intuitively, in a parliamentary system, the threat of a vote of no confidence allows the members of the parliament to push for larger transfers to their constituencies and, as a result, to obtain additional rents for themselves. In a presidential system, on the other hand, the existence of direct elections for the president increases the ability of voters to influence policies, which limits the size of transfers and the amount of rents obtained by legislators, while at the same time allowing the executive leader to extract more rents. The model emphasizes that the balance of powers among agents is distinct under each regime: the legislative has more control over policies under parliamentary systems, while both voters and the executive leader have more power under presidential systems. Interestingly, our analysis shows that not only do direct elections strengthen the political influence of voters and the executive, but also that these two phenomena are intrinsically connected to each other.

The conclusion that taxes and transfers are smaller under presidential systems is consistent with the theoretical results obtained by Persson, Roland and Tabellini (2000) as well as with the empirical evidence provided by Persson and Tabellini (2003, 2004) and Coate and Knight (2011). A novel implication of our analysis is that the size of transfers under presidential systems should be increasing in the quality of institutions available to the median voter. ${ }^{38}$ Intuitively, additional transfers are only worth to the population if a reasonable fraction of the resources is expected to translate into local public goods. This idea is in accordance with the findings obtained by Olken (2006), who studied the performance of an anti-poverty program in Indonesia, showing that the losses arising from corruption may have actually outweighed the intended benefits of the transfers.

Finally, our results concerning the amount of rents extracted by the executive leader and legislators is similar to those obtained by Robinson and Torvik (2009), despite the fact that our analysis is based on a fundamentally different mechanism. Note, however, that our model does not yield any

\footnotetext{
${ }^{38}$ Observe that when the quality of local institutions is high enough, voters want to have taxes and transfers set as high as possible. This is the reason why we use weak inequalities in order to express the results in items $i$ and $i i$ of proposition 1.
} 
unambiguous prediction regarding the total amount of political rents expropriated in each system, which is in contrast with both Persson, Roland and Tabellini (2000), who showed that political rents are always higher under parliamentary regimes, and Robinson and Torvik (2009), who reached exactly the opposite result. Indeed, for any $\bar{\lambda} \in(0,1)$, there are two extreme cases that, in the context of our model, are interesting to consider: $(i)$ when $\lambda^{p}=\lambda^{r}=0$ (i.e. local institutions are completely dysfunctional), political rents are larger under parliamentary systems; while (ii) when $\lambda^{p}=\lambda^{r}=1$ (i.e. local institutions are fully efficient), political rents are larger under presidential systems.

The next proposition compares the quality of the public policies approved under each regime.

Proposition 2. If the number of poor and rich constituencies is such that $n^{p}>n^{r}+1$ and $\Delta=\theta_{H}-\theta_{L}$ is large enough, then there exists a threshold $\bar{\pi}$ such that if $\pi \geq \bar{\pi}$ the expected distance between the public policy and the poor voters' preference is lower under parliamentary systems, $\mathbb{E}\left[\left(x^{\text {pres }}-\theta_{L}\right)^{2}\right]>\mathbb{E}\left[\left(x^{\text {parl }}-\theta_{L}\right)^{2}\right]$.

The vote of no confidence provides extra flexibility to the parliamentary system by allowing legislators to replace a misaligned leader before elections. Indeed, the above proposition shows that the confidence procedure leads to better policies for the majority of voters provided that the probability of post-shock congruence, $\pi$, is sufficiently high. To understand the intuition behind this result, observe that the median legislator's type is determined by aggregating across many representatives. Thus, when $\frac{1}{2}<\pi<1$, the likelihood that the median legislator is aligned with voters is larger than that of any single politician, as "negative shocks" can be cancelled out in the aggregation process. In this case, the parliament is expected to better represent the interests of citizens than the executive. Finally, in order to guarantee that the quality of public policies is indeed higher under parliamentary systems, $\pi$ must be sufficiently large, so that the median legislator is aligned with voters with enough frequency.

From the perspective of the rich voters, it is interesting to consider two particular cases: $(i)$ when $\rho=1$, the preferences of rich and poor citizens are always the same, $\theta^{r}=\theta_{L}$, so that the results discussed above apply to both groups; while $(i i)$ when $\rho=0$, their preferences are always different, $\theta^{r}=\theta_{H}$, so that they have exactly opposite views about the quality of the public policies under each regime. ${ }^{39}$ Thus, our analysis suggests that it should be more difficult to reach an agreement about the choice of form of government in societies with a high degree of preference heterogeneity.

Finally, note that the public policies adopted in each system become increasingly similar as the likelihood of preference shocks decreases, i.e., for any $\pi \in(0,1)$, the absolute difference $\left|x^{\text {pres }}-x^{\text {parl }}\right|$ becomes smaller as $\xi$ decreases and, in particular, $\lim _{\xi \rightarrow 0} x^{\text {pres }}=\lim _{\xi \rightarrow 0} x^{p a r l}=\theta_{L}$. This feature of the model emphasizes the idea that an important element of the difference between presidential and parliamentary systems is related to the way in which they are able to respond to changes in the political environment.

\footnotetext{
${ }^{39}$ Formally, we have: $\mathbb{E}\left[\left(x^{\text {pres }}-\theta_{L}\right)^{2}\right] \geq \mathbb{E}\left[\left(x^{\text {parl }}-\theta_{L}\right)^{2}\right] \leftrightarrow \mathbb{E}\left[\left(x^{\text {pres }}-\theta_{H}\right)^{2}\right] \leq \mathbb{E}\left[\left(x^{\text {parl }}-\theta_{H}\right)^{2}\right]$.
} 


\section{Constitutional Design}

This section analyzes the model developed above to study the preferences of voters and politicians over the form of government. A hypothetical constitutional stage is introduced at the beginning of the period, before any uncertainty over policy preferences is realized. It is assumed that every aspect of the model is common knowledge and that agents know their future social status and political role in the society. Following Buchanan and Tullock (1962), we study the issue of constitutional design from a positive point of view. Our main goal is to investigate the reasons behind the institutional choices of the various population groups, assuming that, at least in the medium run, citizens (poor and rich) and office-holders (executive leader and legislators) are to remain in their respective social and political positions.

The next proposition characterizes the constitutional preferences of politicians.

Proposition 3. With respect to the constitutional preferences of office-holders:

i. The executive leader's expected utility is always higher under presidential systems:

$$
\mathbb{E}\left(V_{e}^{\text {pres }}\right)>\mathbb{E}\left(V_{e}^{\text {parl }}\right)
$$

ii. There exists $\eta \in(0,1)$ such that if $\operatorname{Pr}\left(\theta_{l}=\theta_{l^{m}}\right) \geq \eta$, then the expected utility of legislator $l$ is higher under parliamentary systems:

$$
\mathbb{E}\left(V_{l}^{\text {pres }}\right)<\mathbb{E}\left(V_{l}^{\text {parl }}\right)
$$

According to our analysis, the executive leader prefers a presidential system, where the certainty of a fixed term in office provides insulation against the checks of voters and the congress, while the legislators, on the other hand, tend to prefer a parliamentary system, where the confidence procedure allows them to exert a more active role in the political process. ${ }^{40}$ Note that in this case each representative is able to extract more rents and, conditional on belonging to the majority in congress, to obtain better public policies for themselves. Thus, the parliamentary regime is preferred by a legislator if the probability of him belonging to the majority is sufficiently large, i.e. $\operatorname{Pr}\left(\theta_{l}=\theta_{l^{m}}\right) \geq \eta$, where the exact threshold $\eta$ depends on the amount of rents that he is able to extract under each system. Moreover, the analysis also implies that the legislators representing the poor are relatively more likely to prefer the parliamentary system, given that they belong to the majority coalition with greater likelihood.

We now turn to the constitutional preferences of citizens. The next results are derived under the assumptions required for proposition 2. We start by characterizing the conditions under which the poor voters prefer each regime.

\footnotetext{
${ }^{40}$ As discussed before, this result is consistent with the evidence that the majority of legislators in Brazil, around $74 \%$, were in favour of a parliamentary regime.
} 
Proposition 4. (Poor voters) For any given level of income $0<y^{p}<1$, we have that:

i. If $\lambda^{p}$ and $\pi$ are small enough, then the expected utility of the poor voters is higher under presidential systems.

ii. If $\lambda^{p}$ and $\pi$ are large enough, then the expected utility of the poor voters is higher under parliamentary systems.

The poor voters prefer a presidential system of government whenever the quality of local institutions, $\lambda^{p}$, is weak and the probability of post-shock congruence, $\pi$, is low. In this case, a large fraction of the transfers is diverted by legislators due to the lack of institutional protection at the local level. Furthermore, public policies are expected to be worse under parliamentary systems given that the median legislator cannot be trusted to represent the voters' preferences with high likelihood. Under these conditions, it is best for the poor to keep the ability to check the executive leader through direct elections. This allows them to impose a limit on the size of taxes and transfers as well as to demand policies that are more in line with their own preferences. Conversely, the parliamentary system is preferred whenever the quality of local institutions and the probability of post-shock congruence are both large enough. Overall, our results emphasize that the parliamentarism is the regime which is most "intensive" in political institutions in that it requires a strong system of protection against expropriation, particularly at the local level, and a class of politicians that can be trusted to represent well the interests of voters.

Finally, we compare the constitutional preferences of rich and poor voters, focusing on the following utility difference:

$$
\Omega \equiv \mathbb{E}\left(U^{r, p a r l}-U^{r, p r e s}\right)-\mathbb{E}\left(U^{p, p a r l}-U^{p, p r e s}\right),
$$

where $U^{j, k}$ represents the utility of group $j \in\{p, r\}$ under regime $k \in\{$ pres, parl $\}$. Intuitively, $\Omega$ provides a measure of how the relative preference towards the parliamentary system differs between rich and poor voters. For instance, if $\Omega>(<) 0$, then the rich citizens prefer parliamentarism relatively more (less) than the poor. We assume that the incentive compatibility constraint on the rich legislators is always binding, so that we can focus on the more interesting case where variations in $\lambda^{r}$ have an actual impact on rents. The next proposition summarizes our main conclusions.

Proposition 5. (Rich voters) Ceteris paribus, we have:

i. As $\lambda^{r}$ increases, the rich voters prefer the parliamentary system more than the poor:

$$
\frac{\partial \Omega}{\partial \lambda^{r}}>0
$$

ii. As $y^{r}$ increases, the rich voters prefer the parliamentary system less than the poor:

$$
\frac{\partial \Omega}{\partial y^{r}} \leq 0
$$


with strict inequality when $\mathbb{E}\left(\tau^{\text {pres }}\right)<1$.

The welfare cost generated by the expropriation of rents by legislators is not equally distributed across the population. The better quality of the local institutions available to the rich, $\lambda^{r}>\lambda^{p}$, allows them to obtain more benefits from the larger transfers received under parliamentary systems. At the same time, rich voters are more impacted by the higher taxes levied under parliamentary systems, given that, in our model, taxation is proportional to income, which makes the presidential regime more attractive to them. Interestingly, these results suggest that income per se cannot account for the fact that the rich citizens in Brazil were more likely to vote for the parliamentary system. In fact, to the best of our knowledge, discussions about taxation and redistribution did not arise at all during the referendum. ${ }^{41}$ Instead, the model highlights that an important reason behind the empirical evidence presented above can be attributed to differences in the quality of local accountability institutions across the population.

Observe that the above result does not allow us to determine the sign of $\Omega$. In order to do so, we would have to examine the model for particular combinations of the parameters. Here, we focus on a special case which, in our opinion, captures the main features of the political and institutional environment in Brazil and other developing countries. Specifically, we consider a situation where $\lambda^{p}$ and $\pi$ are small and $y^{r}=y^{p}$, which we impose in order to shut down redistribution in the model. ${ }^{42}$

Corollary 1. Suppose that $\lambda^{p}$ and $\pi$ are small enough and $y^{r}=y^{p}$. Then, for any $\lambda^{r}>\lambda^{p}$, we have:

$$
\mathbb{E}\left(U^{p, p a r l}\right)<\mathbb{E}\left(U^{p, p r e s}\right)
$$

and

$$
\Omega=\mathbb{E}\left(U^{r, p a r l}-U^{r, p r e s}\right)-\mathbb{E}\left(U^{p, p a r l}-U^{p, p r e s}\right)>0
$$

Therefore, when the quality of the local institutions available to the poor is low and the congress cannot be trusted to represent the interests of voters, then: $(i)$ poor citizens prefer a presidential rather than a parliamentary system, and (ii) rich citizens prefer a parliamentary system relatively more than the poor.

\section{Conclusion}

This paper has studied the main factors that determine the constitutional preferences of citizens for the form of government. We have focused on the case of Brazil, where a referendum in 1993

\footnotetext{
${ }^{41}$ We believe that the lack of discussion about these issues is reasonable, especially considering that to associate a particular political regime with precise implications in terms of taxation and redistribution would require an extreme form of rationality on the part of voters. Moreover, note that the insights from Persson, Roland and Tabellini (1997, 2000) about redistribution policies under presidential and parliamentary systems were still unavailable even to scholars at that time.

${ }^{42}$ Note that our qualitative result would remain unchanged as long as the income difference, $y^{r}-y^{p}$, is not too high.
} 
allowed the population to choose between a presidential and a parliamentary system of government. Using a unique data set consisting of the results of the referendum, we show that, while the Brazilian population in general voted in favour of a presidential system, there exists a strong positive correlation between income per capita and the percentage of votes cast for a parliamentary regime in each municipality. We also document that a common reason for rejecting a parliamentary system was the absence of direct elections for the executive in connection with the lack of confidence in the congress.

We have proposed a model to explain the general pattern of the results of the referendum. The analysis was based on a fundamental difference between the two regimes of government: while in presidential systems the executive leader is directly elected by voters and has a fixed term in office, in parliamentary systems the executive leader is appointed by the parliament and may be replaced if he receives a vote of no confidence. We have shown that the parliamentary regime requires a strong system of protection against expropriation, particularly at the local level, and a class of politicians that can be trusted to represent well the interests of voters. We have also shown that the poor groups in the population tend to prefer a presidential system because the lower quality of their local accountability institutions makes them more vulnerable to expropriation of rents by legislators.

This paper contributes to the literature on endogenous political institutions by studying a particular case of constitutional reform. While we do not contend that the results of our analysis apply irrespective of the political and institutional context, we believe that the model highlights some of the key factors involved in the choice of political regime. As pointed out by North (1990), the study of historical events provides a useful way to identify the main elements behind the process of institutional change. This paper proposes the use of referendum data, in connection with a formal theoretical analysis, as a valuable source of information about the preferences of the population on certain political issues. We believe that a similar approach could be fruitfully applied to the study of other institutions, given the possible existence of data on several potentially interesting questions. 


\section{References}

[1] Acemoglu, D. and S. Johnson. 2005. "Unbundling Institutions." Journal of Political Economy, 113(5): 949-95.

[2] Acemoglu, D. and J. A. Robinson. 2000. "Why Did the West Extend the Franchise? Democracy, Inequality and Growth in Historical Perspective." Quarterly Journal of Economics, 115(4): 938-63.

[3] Acemoglu, D. and J. A. Robinson. 2001. "A Theory of Political Transitions." American Economic Review, 91(4): 938-63.

[4] Acemoglu, D. and J. A. Robinson. 2006. "Economic Origins of Dictatorship and Democracy." Cambridge: Cambridge University Press.

[5] Acemoglu, D., J. A. Robinson and R. Torvik. 2011. "Why do Voters Dismantle Checks and Balances?" Working paper, Massachusetts Institute of Technology.

[6] Aghion, P., A. Alesina and F. Trebbi. 2004. "Endogenous Political Institutions." Quarterly Journal of Economics, 119(2): 565-611.

[7] Aghion, P. and P. Bolton. 2003. "Incomplete Social Contracts." Journal of the European Economic Association, 1(1): 38-67.

[8] Ames, B. 1995. "Electoral Rules, Constituency Pressures, and Pork Barrel: Bases of Voting in the Brazilian Congress." Journal of Politics, 57(2): 324-43.

[9] Ames, B. 2001. "The Deadlock of Democracy in Brazil." Ann Arbor: University of Michigan Press.

[10] Bonavides, P. and P. Andrade. 2004. Historia Constitucional do Brasil. Brasilia: OAB Editora.

[11] Buchanan, J. and G. Tullock. 1962. The Calculus of Consent. Ann Arbor: University of Michigan Press.

[12] Cheibub, J. A. 2007. Presidentialism, Parliamentarism and Democracy. New York: Cambridge University Press.

[13] Coate, S. and B. Knight. 2011. "Government Form and Public Spending: Theory and Evidence from U.S. Municipalities." American Economic Journal: Public Policy, forthcoming.

[14] Crisp, B. F. and S. W. Desposato. 2004. "Constituency Building in Multimember Districts: Collusion or Conflict?" Journal of Politics, 66(1): 136-56.

[15] Crisp, B. F. and R. E. Ingall. 2002. "Institutional Engineering and the Nature of Representation: Mapping the Effects of Electoral Reform in Colombia." American Journal of Political Science, 46(4): 733-48. 
[16] Easter, G. M. 1997. "Preference for Presidentialism: Postcommunist Regime Change in Russia and the NIS." World Politics, 49: 184-211.

[17] Ferraz, C. and F. Finan. 2008. "Exposing Corrupt Politicians: The Effects of Brazil's PubliclyReleased Audits on Electoral Outcomes." Quarterly Journal of Economics, 123(3): 703-45.

[18] Ferraz, C. and F. Finan. 2011. "Electoral Accountability and Corruption: Evidence from the Audits of Local Government." American Economic Review, 101: 1274-1311.

[19] Fleischer, D. 1976. "Concentração e Dispersão Eleitoral: Um Estudo da Distribuição Geográfica do Voto em Minas Gerais (1966-1974)." Revista Brasileira de Estudos Políticos, 43: 333-60.

[20] Fleischer, D. 1997. "Political Corruption in Brazil." Crime, Law and Social Change, 25: 297321.

[21] Hirano, S. 2006. "Electoral Institutions, Hometowns, and Favored Minorities: Evidence from Japanese Electoral Reforms." World Politics 58(1): 51-82.

[22] Kunicova, J. and S. Rose-Ackerman. 2005. "Electoral Rules and Constitutional Structures as Constraints on Corruption." British Journal of Political Science, 35(4): 573-606.

[23] Lamounier, B. 1992. "Parliamentarism in Brazil", in Arend Lijphart, (ed.), Parliamentary versus Presidential Government, New York: Oxford University Press, 133-36.

[24] Lederman, D., N. Loayza and R. Soares. 2005. "Accountability and Corruption: Political Institutions Matter." Economics and Politics, 17(1): 1-35.

[25] Lijphart, A. 1992. "Democratization and Constitutional Choices in Czecho-Slovakia, Hungary, and Poland, 1989-1991." Journal of Theoretical Politics, 4: 207-223.

[26] Linz, J. J. 1978. The Breakdown of Democratic Regimes. Crisis, Breakdown and Reequilibration. Baltimore: Johns Hopkins University Press.

[27] Linz, J. J. 1990. "The Perils of Presidentialism." Journal of Democracy, 1(1): 51-69.

[28] Litschig, S. and Y. Zamboni. 2011. "Judicial Presence and Rent Extraction." Working Paper, Universitat Pompeu Fabra.

[29] Mainwaring, S. and M. S. Shugart. 1997. Presidentialism and Democracy in Latin America. Cambridge: Cambridge University Press.

[30] Myerson, R. B. 1993. "Incentives to Cultivate Favored Minorities Under Alternative Electoral Systems." American Political Science Review, 87(4): 856-69.

[31] North, D. 1990. Institutions, Institutional Change and Economic Performance. Cambridge: Cambridge University Press. 
[32] Oates, W. E. 1999. "An Essay on Fiscal Federalism." Journal of Economic Literature, 37(3): 1120-49.

[33] Olken, B. 2006. "Corruption and the Costs of Redistribution." Journal of Public Economics, 90(4-5): 853-70.

[34] Persico, N., A. Silverman and J. Rodriguez-Pueblita. 2011. "Factions and Political Competition." Journal of Political Economy, 119(2): 241-288.

[35] Persson, T. and G. Tabellini. 2003. The Economic Effects of Constitutions: What do the Data Say? Cambridge: MIT Press.

[36] Persson, T. and G. Tabellini. 2004. "Constitutional rules and fiscal policy outcomes." American Economic Review, 94: 25-46.

[37] Persson, T., G. Roland and G. Tabellini. 1997. "Separation of Powers and Political Accountability." Quarterly Journal of Economics, 112(4): 1163-202.

[38] Persson, T., G. Roland and G. Tabellini. 2000. "Comparative Politics and Public Finance." Journal of Political Economy, 108(6): 1121-61.

[39] Pinheiro, A. C. and C. Cabral. 1999. "Credit Markets in Brazil: The Role of Judicial Enforcement and Other Institutions." IDB Working Paper, $\mathrm{n}^{o} 104$.

[40] Prud'homme, R. 1995. "On the Dangers of Decentralization." World Bank Res. Observer, 10(2): 201-20.

[41] Richardson, B. M. 1997. "Japanese Democracy: Power, Coordination, and Performance." New Haven: Yale University Press.

[42] Robinson, J. A. and R. Torvik. 2009. "Endogenous Presidentialism." Working paper, Harvard University.

[43] Shugart, M. S. and J. M. Carey. 1992. Presidents and Assemblies: Constitutional Design and Electoral Dynamics. Cambridge: Cambridge University Press.

[44] Silva, J. 1990. "Presidencialismo e Parlamentarismo no Brasil." Rev. de Ciencia Politica, 33(1): p.14.

[45] Stepan, A. and C. Skach. 1993. "Constitutional Frameworks and Democratic Consolidation: Parlamentarism versus Presidentialism." World Politics, 46(1): 1-22.

[46] Tanzi, V. 1995. "Fiscal Federalism and Decentralization: A Review of Some Efficiency and Macroeconomic Aspects." Annual World Bank Conference on Development Economics, 295316. 
[47] Trebbi, F., P. Aghion and A. Alesina. 2008. "Choosing Electoral Rules: Theory and Evidence from US Cities." Quarterly Journal of Economics, 123(1): 325-57.

[48] Ticchi, D. and A. Vindigni. 2010. "Endogenous Constitutions." Economic Journal, 120(543): 1-39. 


\section{Appendix A: Proofs (NOT FOR PUBLICATION)}

\section{A.1 Lemma 1}

The Lagrangian for problem (8) can be expressed as:

$$
\begin{aligned}
\mathcal{L}= & (1-\tau) y^{p}+\frac{1}{\alpha} \ell^{p}(\varphi)^{\alpha}-\frac{1}{2}\left(x-\theta_{L}\right)^{2}-\psi\left(n \varphi+s_{e}-n \tau\right) \\
& -\zeta\left(\kappa-s_{e}+\frac{1}{2}\left(x-\theta_{e}\right)^{2}-1_{\left\{\theta_{e} \neq \theta_{l^{m}}\right\}} \frac{\Delta^{2}}{8}\right)-\nu_{1}\left(\varphi^{o}-\varphi\right)-\nu_{2}\left(\frac{1}{2}\left(x-\theta_{l^{m}}\right)^{2}-\frac{\Delta^{2}}{8}\right) \\
& -\mu(\tau-1)
\end{aligned}
$$

where $\psi, \zeta, \nu_{1}, \nu_{2}, \mu$ are the multipliers associated with $(B C),\left(I C_{e}\right),\left(A P_{1}\right),\left(A P_{2}\right)$ and $\tau \leq 1$, respectively. The first-order conditions with respect to $\tau, \varphi, s_{e}$ and $x$ yield:

$$
\begin{gathered}
\psi=\frac{y^{p}+\mu}{n} \\
\ell^{p}(\varphi)^{\alpha-1} \lambda^{p}=n \psi-\nu_{1} \\
\zeta=\psi \\
\left(x-\theta_{L}\right)+\zeta\left(x-\theta_{e}\right)+\nu_{2}\left(x-\theta_{l^{m}}\right)=0
\end{gathered}
$$

The optimal level of transfers is such that:

$$
\varphi=\max \left\{\varphi^{o}, \widehat{\varphi}\right\}
$$

where $\widehat{\varphi}$ is implicitly determined by $\ell^{p}(\widehat{\varphi})^{\alpha-1} \lambda^{p}=n \psi$. The multiplier $\psi$ measures the marginal cost of taxation. Note that when the constraint $\tau \leq 1$ is not binding we must have $\psi=\frac{y^{p}}{n}$, so that $\ell^{p}(\widehat{\varphi})^{\alpha-1} \lambda^{p}=y^{p}$. Thus, it follows from equation (24) that transfers $\varphi$ are (weakly) increasing in $\lambda^{p}$ and (weakly) decreasing in $y^{p}$.

Next, observe from equation (23) that the public policy $x$ is a weighted average of the preferences of voters and office-holders. The weight attached to the president's preference, $\zeta>0$, measures the cost of providing him with additional rents, so that $s_{e}$ and $x$ are optimally chosen in order to equalize their marginal rates of "return". From the incentive compatibility constraint, it then follows that political rents are given by:

$$
s_{e}=\kappa+\Psi(x ; \boldsymbol{\theta})
$$

where $\Psi(x ; \boldsymbol{\theta}) \equiv \frac{1}{2}\left(x-\theta_{e}\right)^{2}-1_{\left\{\theta_{e} \neq \theta_{l} m\right\}} \frac{\Delta^{2}}{8} \geq 0$. Note that when the constraint $\tau \leq 1$ is not binding we have $\zeta=\frac{y^{p}}{n}<1$ and the public policy $x\left(\theta_{e}, \theta_{l^{m}}\right)$ is given by: $x\left(\theta_{L}, \theta_{L}\right)=\theta_{L}, x\left(\theta_{L}, \theta_{H}\right)$ $=\frac{\theta_{L}+\theta_{H}}{2}, x\left(\theta_{H}, \theta_{L}\right)=\frac{\theta_{L}+\left(y^{p} / n\right) \theta_{H}}{1+\left(y^{p} / n\right)}$ and $x\left(\theta_{H}, \theta_{H}\right)=\max \left\{\frac{\theta_{L}+\left(y^{p} / n\right) \theta_{H}}{1+\left(y^{p} / n\right)}, \frac{\theta_{L}+\theta_{H}}{2}\right\}=\frac{\theta_{L}+\theta_{H}}{2}$, so that $\left|x\left(\theta_{H}, \theta_{l^{m}}\right)-\theta_{L}\right| \geq\left|x\left(\theta_{L}, \theta_{l^{m}}\right)-\theta_{L}\right|$ for any $\theta_{l^{m}} \in\left\{\theta_{L}, \theta_{H}\right\}$. Substituting these expressions into $\Psi(x ; \boldsymbol{\theta})$, we obtain $\Psi\left(x\left(\theta_{L}, \theta_{L}\right)\right)=\Psi\left(x\left(\theta_{L}, \theta_{H}\right)\right)=0, \Psi\left(x\left(\theta_{H}, \theta_{L}\right)\right)=\frac{1}{2}\left(\left(1 /\left(1+\frac{y^{p}}{n}\right)\right)^{2}-\frac{1}{4}\right) \Delta^{2}$ 
$>0$ and $\Psi\left(x\left(\theta_{H}, \theta_{H}\right)\right)=\frac{1}{8} \Delta^{2}>0$. Thus, it follows from equation (25) that $s_{e} \geq \kappa$, with strict inequality when $\theta_{e}=\theta_{H}$; from the budget constraint we have $\varphi \leq 1-\frac{\kappa}{n}$.

Finally, the tax rate is residually determined by $\tau=\varphi+\frac{1}{n} s_{e}$ and must satisfy $\tau \leq 1$. Observe that as $\Delta=\theta_{H}-\theta_{L}$ rises, the amount of rents required to incentivize a misaligned president increases, so that the constraint $\tau \leq 1$ must eventually bind. ${ }^{43}$ At this point, the marginal cost of taxation, $\psi$, rises, leading to a possible reduction in the size of transfers relative to the solution characterized in (24). ${ }^{44}$ The public policy is further distorted away from the voters' optimal position, as the weight attached to the executive leader's preference, $\zeta$, increases. This, in turn, reduces the amount of rents that must be paid to the president and helps to relax the constraint $\tau \leq 1$.

\section{A.2 Lemma 2}

At the optimum the budget constraint must be binding, so that $s_{e}=n(\tau-\varphi)$. Thus, the Lagrangian associated with problem (15) can be expressed as:

$$
\mathcal{L}=n(\tau-\varphi)-\frac{1}{2}\left(x-\theta_{e}\right)^{2}-\mu\left(s^{p}\left(1-\frac{\kappa}{n}\right)-s^{p}(\varphi)+\frac{1}{2}\left(x-\theta_{l^{m}}\right)^{2}\right)-\nu n(\tau-\varphi),
$$

where $\mu$ and $\nu$ are the multipliers associated with $(C R)$ and $s_{e} \geq 0$, respectively, and $s^{p}(\cdot)$ is the amount of rents obtained by a legislator from a poor constituency.

Observe that the optimal solution always involves setting $\tau=1$. The first-order condition with respect to $\varphi$ yields:

$$
\mu=\frac{n(1+\nu)}{1-\lambda^{p}}
$$

where the multiplier $\mu$ measures the marginal cost from the point of view of the prime minister of providing additional rents for a poor legislator. The first-order condition with respect to $x$ is given by:

$$
\left(x-\theta_{e}\right)+\mu\left(x-\theta_{l^{m}}\right)=0,
$$

so that the public policy is a weighted average of the preferences of the executive leader and the median legislator and, in particular, $\left|x\left(\theta_{e}, \theta_{H}\right)-\theta_{L}\right|>\left|x\left(\theta_{e}, \theta_{L}\right)-\theta_{L}\right|$ for any $\theta_{e} \in\left\{\theta_{L}, \theta_{H}\right\}$. From the confidence requirement constraint, it, then, follows that the size of transfers must be such that:

$$
s^{p}(\varphi)=s^{p}\left(1-\frac{\kappa}{n}\right)+\frac{1}{2}\left(x-\theta_{l^{m}}\right)^{2},
$$

which implies that $\varphi \geq 1-\frac{\kappa}{n}$, with strict inequality when $x \neq \theta_{l^{m}}$. Therefore, from the budget constraint, $s_{e}=n(1-\varphi)$, we must have that $s_{e} \leq \kappa$.

Observe that when the constraint $s_{e} \geq 0$ is not binding, the cost of raising additional rents for legislators is $\mu=\frac{n}{1-\lambda^{p}}$, i.e. $\nu=0$, and the implemented public policy is given by $x=\frac{\theta_{e}+\left(n / 1-\lambda^{p}\right) \theta_{l^{m}}}{1+\left(n / 1-\lambda^{p}\right)}$.

\footnotetext{
${ }^{43}$ Note from the results above that the expressions $\Psi\left(x\left(\theta_{H}, \theta_{L}\right)\right)$ and $\Psi\left(x\left(\theta_{H}, \theta_{H}\right)\right)$ are strictly increasing in $\Delta$ when $\tau<1$.

${ }^{44}$ Whether there is an actual reduction in transfers depends on whether the constraint $\varphi \geq \varphi^{o}$ is binding or not.
} 
In this case, the required transfers are such that $\varphi=1-\frac{\kappa}{n}$ when $\theta_{e}=\theta_{l^{m}}$ and $s^{p}(\varphi)=s^{p}\left(1-\frac{\kappa}{n}\right)$ $+\frac{1}{2}\left(\frac{1}{1+\left(n / 1-\lambda^{p}\right)}\right)^{2} \Delta^{2}$ when $\theta_{e} \neq \theta_{l^{m}}$. Note that as $\Delta=\theta_{H}-\theta_{L}$ increases, the amount of transfers required to compensate legislators for a distortion in the public policy relative to $x=\theta_{l^{m}}$ rises, so that $s_{e} \geq 0$ must eventually bind. At this point, the marginal cost of providing rents to the poor legislators, $\mu$, increases, which leads to a reduction in the distance between $x$ and $\theta_{l^{m}}$. This, in turn, allows for a decrease in the size of transfers and helps to relax the constraint $s_{e} \geq 0$.

\section{A.3 Proposition 1}

The result that $\tau^{\text {pres }} \leq \tau^{\text {parl }}=1$ follows from part $i$ of Lemmas 1 and 2 . Moreover, since $s_{e}^{\text {pres }} \geq$ $s_{e}^{\text {parl }}$ (part iii of Lemmas 1 and 2), it follows from the budget constraint that $\varphi^{\text {pres }} \leq \varphi^{\text {parl }}$ and, given that $\ell_{i}(\varphi)$ is strictly increasing in $\varphi$, we must have $\ell_{i}^{\text {pres }} \leq \ell_{i}^{\text {parl }}$ for any constituency. Note that $\varphi^{\text {pres }}<\varphi^{\text {parl }}$ and $\ell_{i}^{\text {pres }}<\ell_{i}^{\text {parl }}$ whenever $\theta_{e}=\theta_{H}$ or $\theta_{e} \neq \theta_{l^{m}}$, which implies that $\mathbb{E}\left(\varphi^{\text {pres }}\right)<$ $\mathbb{E}\left(\varphi^{\text {parl }}\right)$ and $\mathbb{E}\left(\ell_{i}^{\text {pres }}\right)<\mathbb{E}\left(\ell_{i}^{\text {parl }}\right)$. The result that $\mathbb{E}\left(s_{e}^{\text {pres }}\right)>\mathbb{E}\left(s_{e}^{\text {parl }}\right)$ follows directly from part iii of Lemmas 1 and 2 , while $\mathbb{E}\left(s_{l}^{\text {pres }}\right) \leq \mathbb{E}\left(s_{l}^{\text {parl }}\right)$ is due to $\varphi^{\text {pres }} \leq \varphi^{\text {parl }}$ combined with the fact that $s_{l}(\varphi)$ is (weakly) increasing in $\varphi$, and strictly so for a legislator representing a poor constituency (from assumption 1).

\section{A.4 Proposition 2}

Let $\Gamma_{i j} \equiv \operatorname{Pr}\left(\theta_{e}=\theta_{i}, \theta_{l^{m}}=\theta_{j}\right)$, where $i, j \in\{L, H\}$. The probability of each configuration of the office-holders' preferences can be expressed as:

$$
\begin{aligned}
\Gamma_{L L}= & (1-\xi)+\xi \pi\left\{\rho \sum_{k=\frac{n+1}{2}}^{n}\left(\begin{array}{l}
n \\
k
\end{array}\right) \pi^{k}(1-\pi)^{n-k}\right. \\
& \left.+(1-\rho) \sum_{j=0}^{n^{r}} \sum_{k=\frac{n+1}{2}-\left(n^{r}-j\right)}^{n^{p}}\left(\begin{array}{c}
n^{r} \\
j
\end{array}\right)\left(\begin{array}{c}
n^{p} \\
k
\end{array}\right) \pi^{j+k}(1-\pi)^{n-j-k}\right\} \\
\Gamma_{L H}= & \xi \pi\left\{\rho \sum_{k=0}^{\frac{n-1}{2}}\left(\begin{array}{c}
n \\
k
\end{array}\right) \pi^{k}(1-\pi)^{n-k}\right. \\
& \left.+(1-\rho) \sum_{j=0}^{n^{r}} \sum_{k=0}^{\frac{n-1}{2}-\left(n^{r}-j\right)}\left(\begin{array}{c}
n^{r} \\
j
\end{array}\right)\left(\begin{array}{c}
n^{p} \\
k
\end{array}\right) \pi^{j+k}(1-\pi)^{n-j-k}\right\}
\end{aligned}
$$




$$
\begin{aligned}
\Gamma_{H L}= & \xi(1-\pi)\left\{\rho \sum_{k=\frac{n+1}{2}}^{n}\left(\begin{array}{l}
n \\
k
\end{array}\right) \pi^{k}(1-\pi)^{n-k}\right. \\
& \left.+(1-\rho) \sum_{j=0}^{n^{r}} \sum_{k=\frac{n+1}{2}-\left(n^{r}-j\right)}^{n^{p}}\left(\begin{array}{c}
n^{r} \\
j
\end{array}\right)\left(\begin{array}{c}
n^{p} \\
k
\end{array}\right) \pi^{j+k}(1-\pi)^{n-j-k}\right\} \\
\Gamma_{H H}= & \xi(1-\pi)\left\{\rho \sum_{k=0}^{\frac{n-1}{2}}\left(\begin{array}{c}
n \\
k
\end{array}\right) \pi^{k}(1-\pi)^{n-k}\right. \\
& \left.+(1-\rho) \sum_{j=0}^{n^{r}} \sum_{k=0}^{\frac{n-1}{2}-\left(n^{r}-j\right)}\left(\begin{array}{c}
n^{r} \\
j
\end{array}\right)\left(\begin{array}{c}
n^{p} \\
k
\end{array}\right) \pi^{j+k}(1-\pi)^{n-j-k}\right\}
\end{aligned}
$$

Observe that the expected quadratic distance between the public policy and the median voters' preference is given by:

$$
\mathbb{E}\left[\left(x-\theta_{L}\right)^{2}\right]=\underbrace{\Gamma_{L H}\left(x\left(\theta_{L}, \theta_{H}\right)-\theta_{L}\right)^{2}}_{\text {case } I}+\underbrace{\Gamma_{H L}\left(x\left(\theta_{H}, \theta_{L}\right)-\theta_{L}\right)^{2}}_{\text {case } I I}+\underbrace{\Gamma_{H H}\left(x\left(\theta_{H}, \theta_{H}\right)-\theta_{L}\right)^{2}}_{\text {case } I I I}
$$

where we have used the fact that $x\left(\theta_{L}, \theta_{L}\right)=\theta_{L}$ under both regimes.

Next, note that when $\Delta=\theta_{H}-\theta_{L}$ is large enough we can always guarantee that:

$$
\left(x^{\text {pres }}\left(\theta_{L}, \theta_{H}\right)-\theta_{L}\right)^{2}<\left(x^{\text {parl }}\left(\theta_{L}, \theta_{H}\right)-\theta_{L}\right)^{2}
$$

and

$$
\left(x^{\text {pres }}\left(\theta_{H}, \theta_{L}\right)-\theta_{L}\right)^{2}>\left(x^{\text {parl }}\left(\theta_{H}, \theta_{L}\right)-\theta_{L}\right)^{2},
$$

that is, when $\theta_{e}=\theta_{L}$ and $\theta_{l^{m}}=\theta_{H}$ (case $I$ ), the public policy is closer to $\theta_{L}$ under presidential systems, while, when $\theta_{e}=\theta_{H}$ and $\theta_{l^{m}}=\theta_{L}$ (case $I I$ ), the public policy is closer to $\theta_{L}$ under parliamentary systems. The requirement that $\Delta$ be large enough is sufficient to rule out the cases where $\left(x^{\text {pres }}\left(\theta_{H}, \theta_{L}\right)-\theta_{L}\right)^{2} \leq\left(x^{\text {parl }}\left(\theta_{H}, \theta_{L}\right)-\theta_{L}\right)^{2}$. Intuitively, this situation occurs whenever $y^{p}$ and $\Delta$ are small enough, so that it is "inexpensive" for the poor to incentivize a misaligned president to propose a policy that is very close to $\theta_{L}$. As we have shown in the proofs of Lemmas 1 and 2 , the weight in the public policy attached to the preference of a misaligned leader increases with $\Delta$ in a presidential system (see equation (23) and discussion in the last paragraph of the proof of Lemma 1), while the weight attached to the preference of the median legislator increases with $\Delta$ in a parliamentary system (see equation (27) and discussion in the last paragraph of the proof of Lemma 2). Finally, observe that when $\theta_{e}=\theta_{H}$ and $\theta_{l^{m}}=\theta_{H}$ (case $I I I$ ) the parliamentary system is always worse for the poor:

$$
\left(x^{\text {pres }}\left(\theta_{H}, \theta_{H}\right)-\theta_{L}\right)^{2}<\left(x^{\text {parl }}\left(\theta_{H}, \theta_{H}\right)-\theta_{L}\right)^{2},
$$


since $x^{\text {parl }}\left(\theta_{H}, \theta_{H}\right)=\theta_{H}$ and $x^{\text {pres }}\left(\theta_{H}, \theta_{H}\right)<\theta_{H} \cdot{ }^{45}$

Thus, in order to guarantee that the parliamentary regime yields better policies in expectation, the configuration of preferences $\theta_{e}=\theta_{H}$ and $\theta_{l^{m}}=\theta_{L}$ (case $I I$ ) must occur with high enough frequency relative to the other two possibilities. Here, we show that there always exists $\pi$ large enough, so that the probability ratio $\frac{\Gamma_{H L}}{\Gamma_{L H}+\Gamma_{H H}}$ can always be made arbitrarily high. Formally, we prove that $\lim _{\pi \rightarrow 1} \frac{\Gamma_{H L}}{\Gamma_{L H}+\Gamma_{H H}} \rightarrow+\infty$, provided that $n^{p}>n^{r}+1$, so that there always exist a threshold $\bar{\pi}$ such that if $\pi>\pi$ the parliamentary system is preferred in terms of the public policies it generates.

Note, first, that the expression for the probability ratio $\frac{\Gamma_{H L}}{\Gamma_{L H}+\Gamma_{H H}}$ is given by:

$$
\begin{gathered}
\frac{\Gamma_{H L}}{\Gamma_{L H}+\Gamma_{H H}}= \\
\frac{(1-\pi)\left\{\rho \sum_{k=\frac{n+1}{2}}^{n}\left(\begin{array}{c}
n \\
k
\end{array}\right) \pi^{k}(1-\pi)^{n-k}+(1-\rho) \sum_{j=0}^{n^{r}} \sum_{k=\frac{n+1}{2}-\left(n^{r}-j\right)}^{n^{p}}\left(\begin{array}{c}
n^{r} \\
j
\end{array}\right)\left(\begin{array}{c}
n^{p} \\
k
\end{array}\right) \pi^{j+k}(1-\pi)^{n-j-k}\right\}}{\left\{\rho \sum_{k=0}^{\frac{n-1}{2}}\left(\begin{array}{c}
n \\
k
\end{array}\right) \pi^{k}(1-\pi)^{n-k}+(1-\rho) \sum_{j=0}^{n^{r}} \sum_{k=0}^{\frac{n-1}{2}-\left(n^{r}-j\right)}\left(\begin{array}{c}
n^{r} \\
j
\end{array}\right)\left(\begin{array}{c}
n^{p} \\
k
\end{array}\right) \pi^{j+k}(1-\pi)^{n-j-k}\right\}}
\end{gathered}
$$

The algebra involved in the proof is straightforward, but lenghty. Here, we simply skecth the main steps of our argument. First, it is possible to show that both the numerator and the denominator of the above expression converge to zero as $\pi$ approaches one:

$$
\begin{gathered}
\lim _{\pi \rightarrow 1}(1-\pi)\left\{\rho \sum_{k=\frac{n+1}{2}}^{n}\left(\begin{array}{l}
n \\
k
\end{array}\right) \pi^{k}(1-\pi)^{n-k}\right. \\
\left.+(1-\rho) \sum_{j=0}^{n^{r}} \sum_{k=\frac{n+1}{2}-\left(n^{r}-j\right)}^{n^{p}}\left(\begin{array}{c}
n^{r} \\
j
\end{array}\right)\left(\begin{array}{c}
n^{p} \\
k
\end{array}\right) \pi^{j+k}(1-\pi)^{n-j-k}\right\}=0
\end{gathered}
$$

and

$$
\lim _{\pi \rightarrow 1}\left\{\rho \sum_{k=0}^{\frac{n-1}{2}}\left(\begin{array}{l}
n \\
k
\end{array}\right) \pi^{k}(1-\pi)^{n-k}+(1-\rho) \sum_{j=0}^{n^{r}} \sum_{k=0}^{\frac{n-1}{2}-\left(n^{r}-j\right)}\left(\begin{array}{c}
n^{r} \\
j
\end{array}\right)\left(\begin{array}{c}
n^{p} \\
k
\end{array}\right) \pi^{j+k}(1-\pi)^{n-j-k}\right\}=0
$$

Intuitively, when $\pi \rightarrow 1$, we have $\Gamma_{L L} \rightarrow 1$ and $\Gamma_{H L}, \Gamma_{L H}, \Gamma_{H H} \rightarrow 0$, i.e. the "dominant" case is $\theta_{e}=\theta_{L}$ and $\theta_{l^{m}}=\theta_{L}$. Next, applying the L'Hospital rule, we can show that the denominator converges to zero faster than the numerator, so that:

$$
\lim _{\pi \rightarrow 1} \frac{\Gamma_{H L}}{\Gamma_{L H}+\Gamma_{H H}} \rightarrow+\infty
$$

The requirement that $n^{p}>n^{r}+1$ is in order to guarantee that there are enough poor representatives

\footnotetext{
${ }^{45}$ The fact that $x^{\text {parl }}\left(\theta_{H}, \theta_{H}\right)=\theta_{H}$ is an immediate consequence of equation (27), while $x^{\text {pres }}\left(\theta_{H}, \theta_{H}\right)<\theta_{H}$ follows from equation (23), which guarantees that the preference of the poor voters, $\theta_{L}$, always receives a strictly positive weight in the public policy.
} 
in the assembly so that $\operatorname{Pr}\left(\theta_{l^{m}}=\theta_{H}\right)$ approaches zero rapidly enough.

\section{A.5 Proposition 3}

Part i. Observe that in a presidential system the incentive compatibility constraint $\left(I C_{e}\right)$ pins down the utility of the executive leader, so that:

$$
V_{e}^{\text {pres }}(\boldsymbol{\theta})=\left\{\begin{array}{cl}
\kappa & \text { if } \theta_{e}=\theta_{l^{m}} \\
\kappa-\frac{1}{8} \Delta^{2} & \text { if } \theta_{e} \neq \theta_{l^{m}}
\end{array}\right.
$$

while, in a parliamentary system, we have:

$$
V_{e}^{\text {parl }}(\boldsymbol{\theta})=\left\{\begin{array}{cl}
\kappa & \text { if } \theta_{e}=\theta_{l^{m}} \\
<\kappa-\frac{1}{8} \Delta^{2} & \text { if } \theta_{e} \neq \theta_{l^{m}}
\end{array}\right.
$$

where the last inequality follows from the fact that $s_{e}^{\text {parl }} \leq \kappa($ Lemma 2$)$ and $\frac{1}{2}\left(x^{\text {parl }}-\theta_{e}\right)^{2} \geq \frac{1}{2}$ $\left(\frac{n \theta_{l^{m}}+\left(1-\lambda^{p}\right) \theta_{e}}{n+\left(1-\lambda^{p}\right)}-\theta_{e}\right)^{2}=\frac{1}{2}\left(\frac{n}{n+\left(1-\lambda^{p}\right)}\right)^{2} \Delta^{2}>\frac{1}{8} \Delta^{2}$ when $\theta_{e} \neq \theta_{l^{m}} .{ }^{46}$ Therefore, it must be that $\mathbb{E}\left(V_{e}^{\text {pres }}\right)>\mathbb{E}\left(V_{e}^{\text {parl }}\right)$

Part ii. In a parliamentary system, the utility of a legislator whose preference is aligned with the median representative is determined by the confidence requirement constraint $(C R)$ :

$$
V_{l}^{\text {parl }}\left(\theta_{l}=\theta_{l^{m}}\right)=s_{l}\left(1-\frac{\kappa}{n}\right)
$$

Observe that the expected utility of this same agent is strictly smaller in a presidential system, since $\mathbb{E}\left(s_{l}^{\text {pres }}\right) \leq s_{l}\left(1-\frac{\kappa}{n}\right)$ and $\mathbb{E}\left(x^{\text {pres }}-\theta_{l^{m}}\right)^{2}>0 .{ }^{47}$ Thus, conditional on belonging to the "winning coalition", a legislator is always better off under a parliamentary system, i.e. $\mathbb{E}\left(V_{l}^{\text {pres }}\left(\theta_{l}=\theta_{l^{m}}\right)\right)$ $<\mathbb{E}\left(V_{l}^{\text {parl }}\left(\theta_{l}=\theta_{l^{m}}\right)\right)$. On the other hand, an agent who is not aligned with the median type may actually do worse under a parliamentary regime, given that in this case the public policy is always implemented far from his preferred position.

Note that the expected utility of a representative can be written, in general, as:

$$
\mathbb{E}\left(V_{l}\right)=\underbrace{\operatorname{Pr}\left(\theta_{l}=\theta_{l^{m}}\right) \mathbb{E}\left(V_{l}\left(\theta_{l}=\theta_{l^{m}}\right)\right)}_{\text {parliamentary sys. preferred }}+\underbrace{\operatorname{Pr}\left(\theta_{l} \neq \theta_{l^{m}}\right) \mathbb{E}\left(V_{l}\left(\theta_{l} \neq \theta_{l^{m}}\right)\right)}_{\text {presidential sys. may be preferred }}
$$

Therefore, as long as the probability that a legislator is aligned with the median type is sufficiently large, we have:

$$
\mathbb{E}\left(V_{l}^{\text {pres }}\right)<\mathbb{E}\left(V_{l}^{\text {parl }}\right)
$$

\footnotetext{
${ }^{46}$ Here, we consider the most favourable case for the prime minister, i.e. when the constraint $s_{e} \geq 0$ is not binding, so that $\mu=\frac{n}{1-\lambda^{p}}$ and $x^{\text {parl }}=\frac{\theta_{e}+\left(n / 1-\lambda^{p}\right) \theta_{l} m}{1+\left(n / 1-\lambda^{p}\right)}$. See discussion in the last paragraph of the proof of Lemma 2 .

${ }^{47}$ The inequality $\mathbb{E}\left(s_{l}^{\text {pres }}\right) \leq s_{l}\left(1-\frac{\kappa}{n}\right)$ is due to the fact that $\varphi^{\text {pres }} \leq 1-\frac{\kappa}{n}$, which in turn follows from $s_{e}^{\text {pres }} \geq \kappa$ (see equation [25]).
} 
Formally, there exists $\eta$ such that if $\operatorname{Pr}\left(\theta_{l}=\theta_{l^{m}}\right) \geq \eta$, then the above expression always holds. In particular, it is guaranteed to be satisfied whenever $\operatorname{Pr}\left(\theta_{l}=\theta_{l^{m}}\right)=1$. The exact value of the threshold $\eta$ depends on the parameters of the model.

\section{A.6 Proposition 4}

Part i. The utility of the poor voters is given by:

$$
U^{p}=\underbrace{(1-\tau) y^{p}+\frac{1}{\alpha} \ell^{p}(\varphi)^{\alpha}}_{\text {term } I}-\underbrace{\frac{1}{2}\left(x-\theta_{L}\right)^{2}}_{\text {term } I I}
$$

Let us first consider term $I$. Observe that when $\lambda^{p}$ is arbitrarily small, i.e. $\lambda^{p} \rightarrow 0$, we have, for any possible configuration of office holders' preference:

$$
\lim _{\lambda^{p} \rightarrow 0}\left\{\left(1-\tau^{\text {pres }}\right) y^{p}+\frac{1}{\alpha} \ell^{p}\left(\varphi^{\text {pres }}\right)^{\alpha}\right\}=\left(1-\tau^{\text {pres }}\right) y^{p}+\frac{1}{\alpha}\left(\beta \omega_{L}\right)^{\alpha}
$$

and

$$
\lim _{\lambda^{p} \rightarrow 0}\left\{\left(1-\tau^{\text {parl }}\right) y^{p}+\frac{1}{\alpha} \ell^{p}\left(\varphi^{\text {parl }}\right)^{\alpha}\right\}=\frac{1}{\alpha}\left(\beta \omega_{L}\right)^{\alpha}
$$

which follows from the fact that $\tau^{\text {parl }}=1$ and $\lim _{\lambda^{p} \rightarrow 0} \ell^{p}(\varphi)=\beta \omega_{L}$ (see equation [7]). Therefore, we have:

$$
\lim _{\lambda^{p} \rightarrow 0}\left\{\left(1-\tau^{\text {pres }}\right) y^{p}+\frac{1}{\alpha} \ell\left(\varphi^{\text {pres }}\right)^{\alpha}\right\} \geq \lim _{\lambda^{p} \rightarrow 0}\left\{\left(1-\tau^{\text {parl }}\right) y^{p}+\frac{1}{\alpha} \ell\left(\varphi^{\text {parl }}\right)^{\alpha}\right\}
$$

with strict inequality when $\tau^{\text {pres }}<1$. Next, consider term $I I$. Note that when $\pi$ is arbitrarily small, i.e. $\pi \rightarrow 0$, we have:

$$
\lim _{\pi \rightarrow 0} \mathbb{E}\left(x^{\text {pres }}-\theta_{L}\right)^{2}<\lim _{\pi \rightarrow 0} \mathbb{E}\left(x^{\text {parl }}-\theta_{L}\right)^{2},
$$

which follows from the fact that in this case the "dominant" configuration of preferences is $\theta_{e}=$ $\theta_{l^{m}}=\theta_{H}$, so that $x^{\text {parl }}=\theta_{H}$ and $x^{\text {pres }}<\theta_{H} \cdot{ }^{48}$ Therefore, combining (44) and (45), we can guarantee that $\mathbb{E}\left(U^{p, p r e s}\right)>\mathbb{E}\left(U^{p, p a r l}\right)$ whenever $\lambda^{p}$ and $\pi$ are sufficiently small.

Part ii. Observe, first, that when $\lambda^{p}$ is large enough, i.e. $\lambda^{p} \rightarrow 1$, we have, for any possible configuration of office holders' preference:

$$
\lim _{\lambda^{p} \rightarrow 1}\left\{\left(1-\tau^{\text {pres }}\right) y^{p}+\frac{1}{\alpha} \ell^{p}\left(\varphi^{\text {pres }}\right)^{\alpha}\right\}=\frac{1}{\alpha}\left(\varphi^{\text {pres }}\right)^{\alpha},
$$

and

$$
\lim _{\lambda^{p} \rightarrow 1}\left\{\left(1-\tau^{\text {parl }}\right) y^{p}+\frac{1}{\alpha} \ell^{p}\left(\varphi^{\text {parl }}\right)^{\alpha}\right\}=\frac{1}{\alpha}\left(\varphi^{\text {parl }}\right)^{\alpha},
$$

\footnotetext{
${ }^{48}$ See discussion in footnote 42.
} 
which follow from the fact that in this case $\tau^{\text {parl }}=\tau^{\text {pres }}=1$ and $\lim _{\lambda^{p} \rightarrow 1} \ell^{p}(\varphi)=\varphi \cdot{ }^{49}$ Thus, we have:

$$
\lim _{\lambda^{p} \rightarrow 1}\left\{\left(1-\tau^{\text {pres }}\right) y^{p}+\frac{1}{\alpha} \ell^{p}\left(\varphi^{\text {pres }}\right)^{\alpha}\right\} \leq \lim _{\lambda^{p} \rightarrow 1}\left\{\left(1-\tau^{\text {parl }}\right) y^{p}+\frac{1}{\alpha} \ell^{p}\left(\varphi^{\text {parl }}\right)^{\alpha}\right\}
$$

since $\varphi^{\text {pres }} \leq \varphi^{\text {parl }}$ (Proposition 1). Moreover, when $\pi$ is large enough, i.e. $\pi \rightarrow 1$, we must have:

$$
\lim _{\pi \rightarrow 1} \mathbb{E}\left(x^{\text {pres }}-\theta_{L}\right)^{2}>\lim _{\pi \rightarrow 1} \mathbb{E}\left(x^{\text {parl }}-\theta_{L}\right)^{2},
$$

which follows from Proposition 2. Therefore, combining (48) and (49), we can guarantee that $\mathbb{E}\left(U^{p, p r e s}\right)<\mathbb{E}_{(}\left(U^{p, p a r l}\right)$, whenever $\lambda^{p}$ and $\pi$ are sufficiently large.

\section{A.7 Proposition 5}

Part i. Observe that:

$$
\frac{\partial \Omega}{\partial \lambda^{r}}=\frac{\partial}{\partial \lambda^{r}}\left\{\mathbb{E}\left(U^{r, p a r l}-U^{r, p r e s}\right)\right\}=\mathbb{E}\left\{\ell^{r}\left(\varphi^{\text {parl }}\right)^{\alpha-1} \varphi^{\text {parl }}-\ell^{r}\left(\varphi^{\text {pres }}\right)^{\alpha-1} \varphi^{\text {pres }}\right\}
$$

To prove that this expression is strictly positive, consider the following derivative:

$$
\frac{\partial}{\partial \varphi}\left\{\ell^{r}(\varphi)^{\alpha-1} \varphi\right\}=\ell^{r}(\varphi)^{\alpha-1} \Lambda
$$

where $\Lambda=1+\frac{(\alpha-1) \varphi}{\ell^{r}(\varphi)} \lambda^{r}$. Using the fact that $\ell^{r}\left(\varphi^{\text {parl }}\right)=\lambda^{r} \varphi+\beta \omega_{L}$, we can write:

$$
\Lambda=1+\frac{(\alpha-1) \varphi}{\lambda^{r} \varphi+\beta \omega_{L}} \lambda^{r}=\frac{\alpha \lambda^{r} \varphi+\beta \omega_{L}}{\lambda^{r} \varphi+\beta \omega_{L}}>0
$$

where the strict inequality comes from the fact that $0<\alpha<1$. Therefore, we have that $\frac{\partial}{\partial \varphi}\left\{\ell^{r}(\varphi)^{\alpha-1} \varphi\right\}>0$. This result, combined with the fact that $\varphi^{\text {parl }} \geq \varphi^{\text {pres }}$, with strict inequality when $\theta_{e} \neq \theta_{l^{m}}$, implies that $\mathbb{E}\left\{\ell^{r}\left(\varphi^{\text {parl }}\right)^{\alpha-1} \varphi^{\text {parl }}\right\}>\mathbb{E}\left\{\ell^{r}\left(\varphi^{\text {pres }}\right)^{\alpha-1} \varphi^{\text {pres }}\right\}$, so that $\frac{\partial \Omega}{\partial \lambda^{r}}>0$.

Part ii. Note that:

$$
\frac{\partial \Omega}{\partial y^{r}}=\frac{\partial}{\partial y^{r}}\left\{\mathbb{E}\left(U^{r, p a r l}-U^{r, p r e s}\right)\right\}=\mathbb{E}\left(1-\tau^{\text {parl }}\right)-\mathbb{E}\left(1-\tau^{\text {pres }}\right),
$$

\footnotetext{
${ }^{49}$ In order to prove that $\tau^{\text {pres }}=1$, suppose by contradiction that $\tau \leq 1$ is not binding. In this case the Lagrangian multiplier associated with this constraint is equal to zero, i.e. $\mu=0$, so that the first-order condition in equation (21) can be expressed as $\left(\varphi^{\text {pres }}\right)^{\alpha-1}=y^{p}$, where we have assumed that $\varphi^{\text {pres }} \geq \varphi^{o}$ holds, i.e. $\nu_{1}=0$ (we will show that this is in fact the case). Observe that since $0<\alpha<1$ and $0<y^{p}<1$ we must have $\varphi^{\text {pres }}=\left(1 / y^{p}\right)^{1-\alpha}>1$ (thus, indeed, $\varphi^{\text {pres }}>\varphi^{o}$ ). But this implies that $\tau^{\text {pres }} \leq 1$ must necessarily bind in equilibrium, which is a contradiction.
} 
which, using the fact that $\tau^{\text {parl }}=1$, yields:

$$
\frac{\partial \Omega}{\partial y^{r}}=\mathbb{E}\left(\tau^{\text {pres }}\right)-1 \leq 0,
$$

with strict inequality when $\mathbb{E}\left(\tau^{\text {pres }}\right)<1$. 


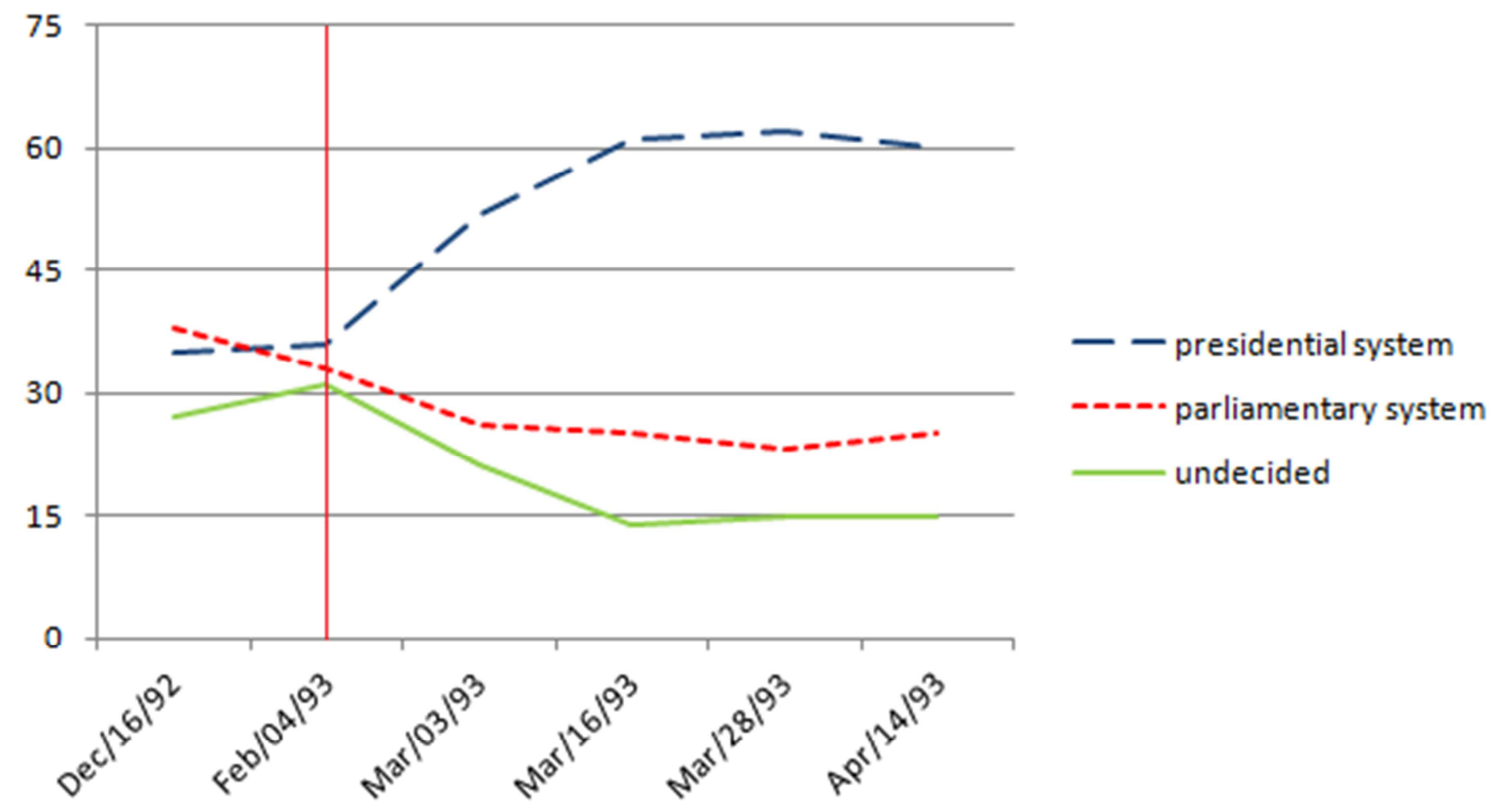

Note. This figure plots the evolution of voting intentions during the months preceding the referendum. The vertical line marks the beginning of the campaigns on TV and radio. Source: Datafolha Institute.

Figure 1: Evolution of Voting Intentions 


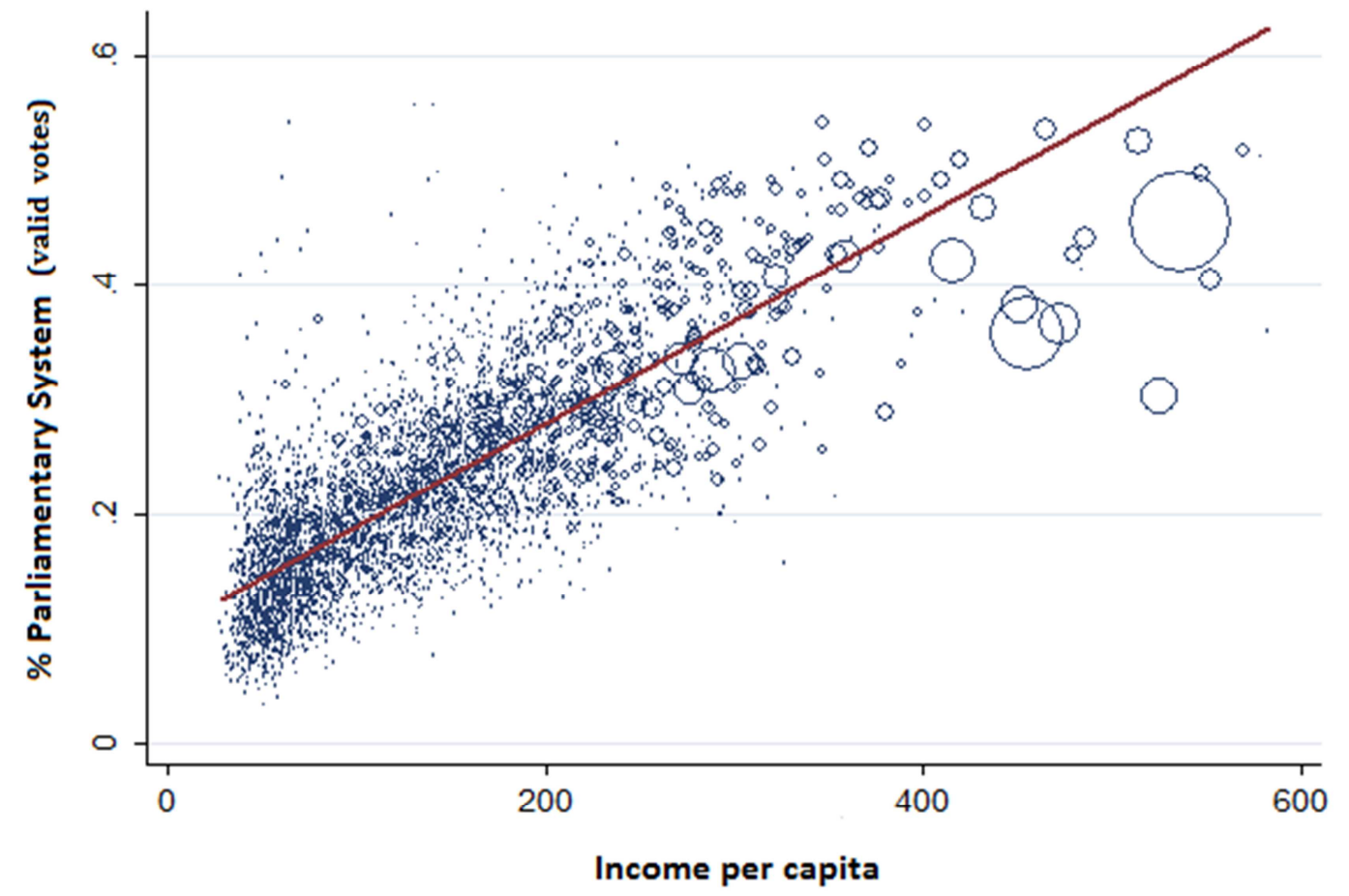

Note. This figure plots the relationship between income per capita and the percentage of votes cast for a parliamentary system among valid votes, i.e. excluding null and blank votes. Each municipality is represented as a circle proportional to its population. The graph displays a linear regression line with $\mathrm{R}^{2}=0.56$.

Figure 2: \% of Valid Votes for a Parliamentary System versus Income per Capita 


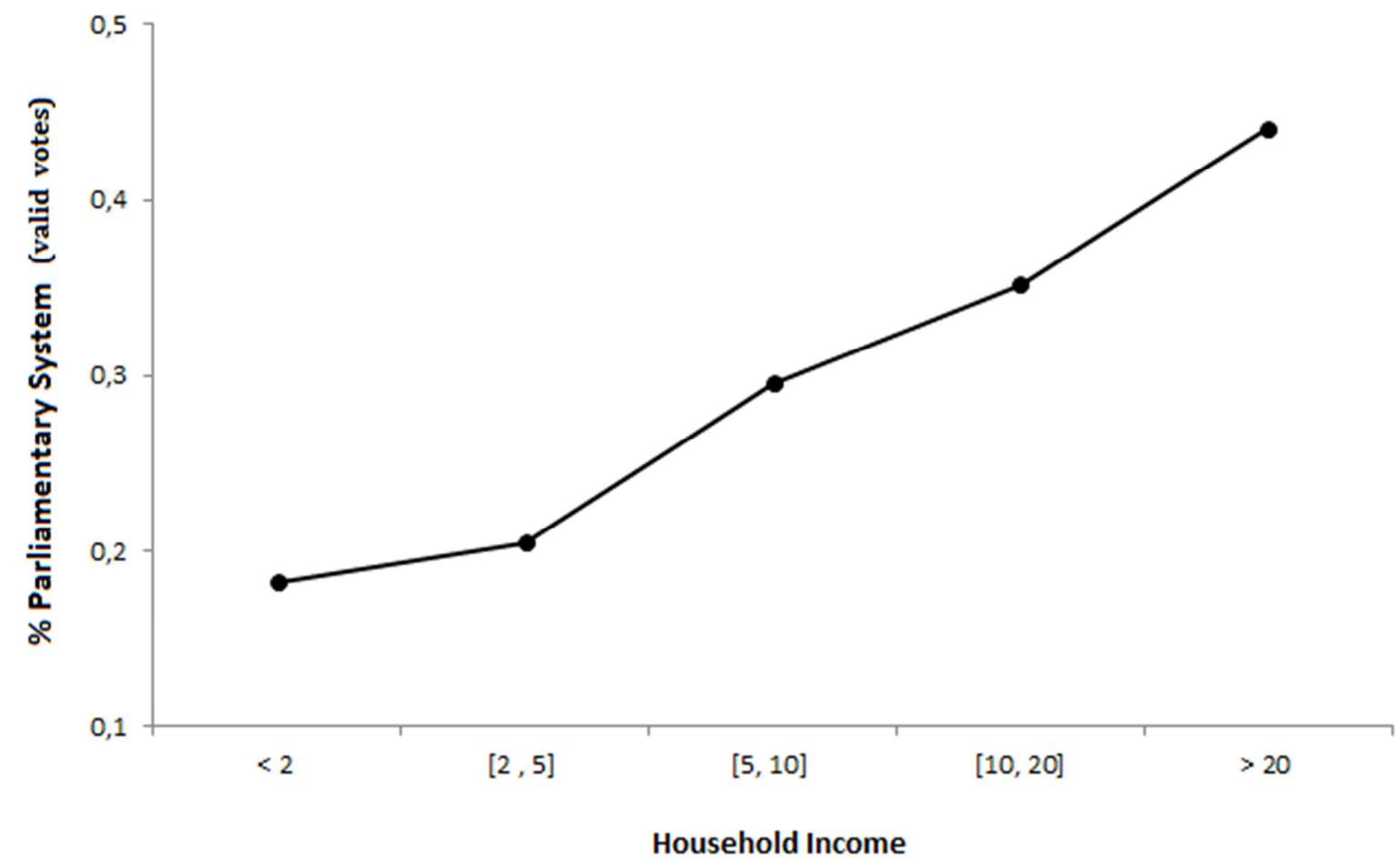

Note. This figure plots the voting intentions for a parliamentary system for different classes of household income (as measured in numbers of minimum wages). The data refers to an opinion survey conducted by the Datafolha Institute on March $28^{\text {th }}{ }_{L} 1993$.

Figure 3: Voting Intentions for a Parliamentary System 


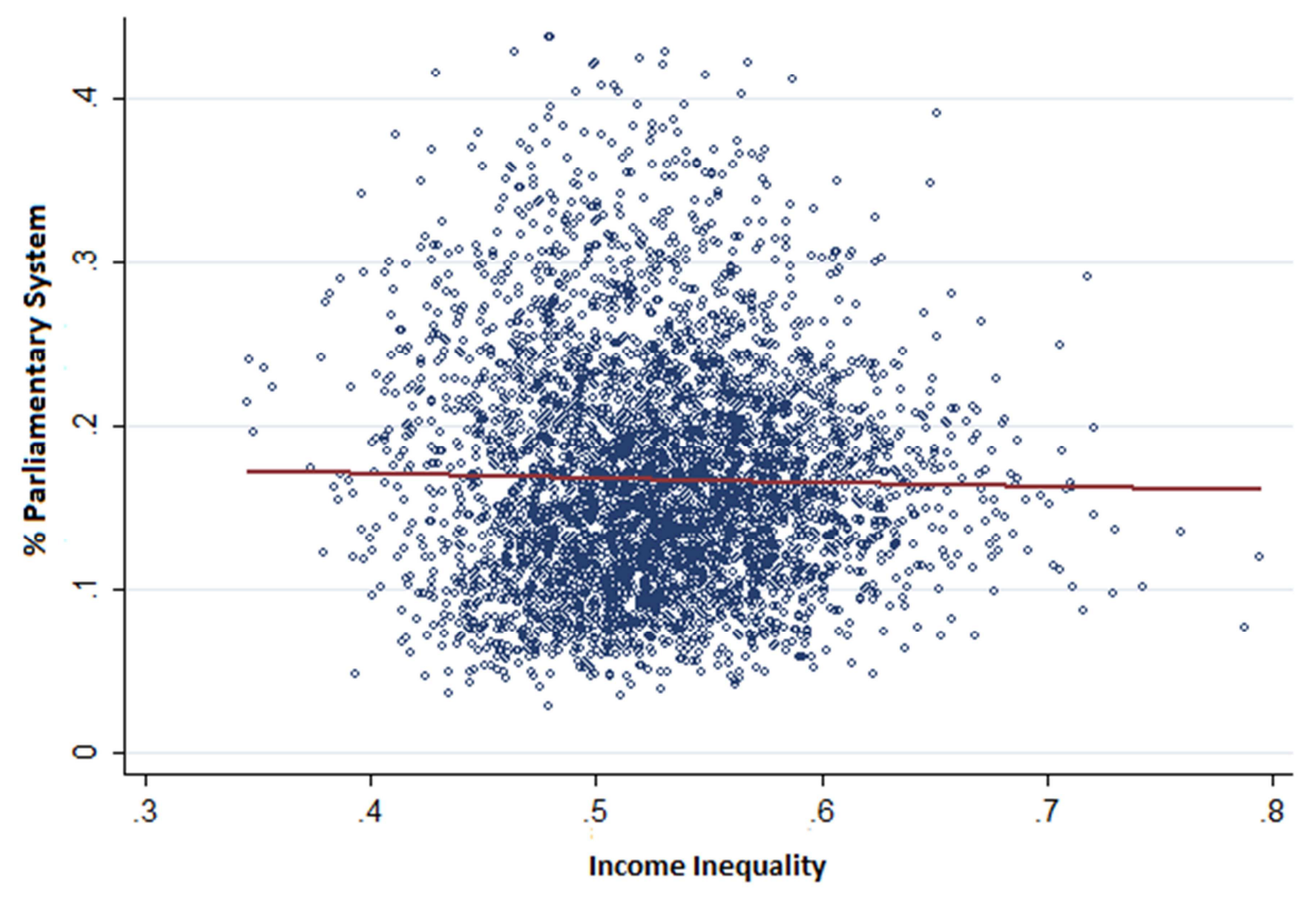

Note. This figure plots the relationship between income inequality, as measured by the gini coefficient, and the percentage of votes cast for a parliamentary system. The graph displays a linear regression line with $\mathrm{R}^{2}=0$.

Figure 4: \% of Votes for a Parliamentary System versus Income Inequality 


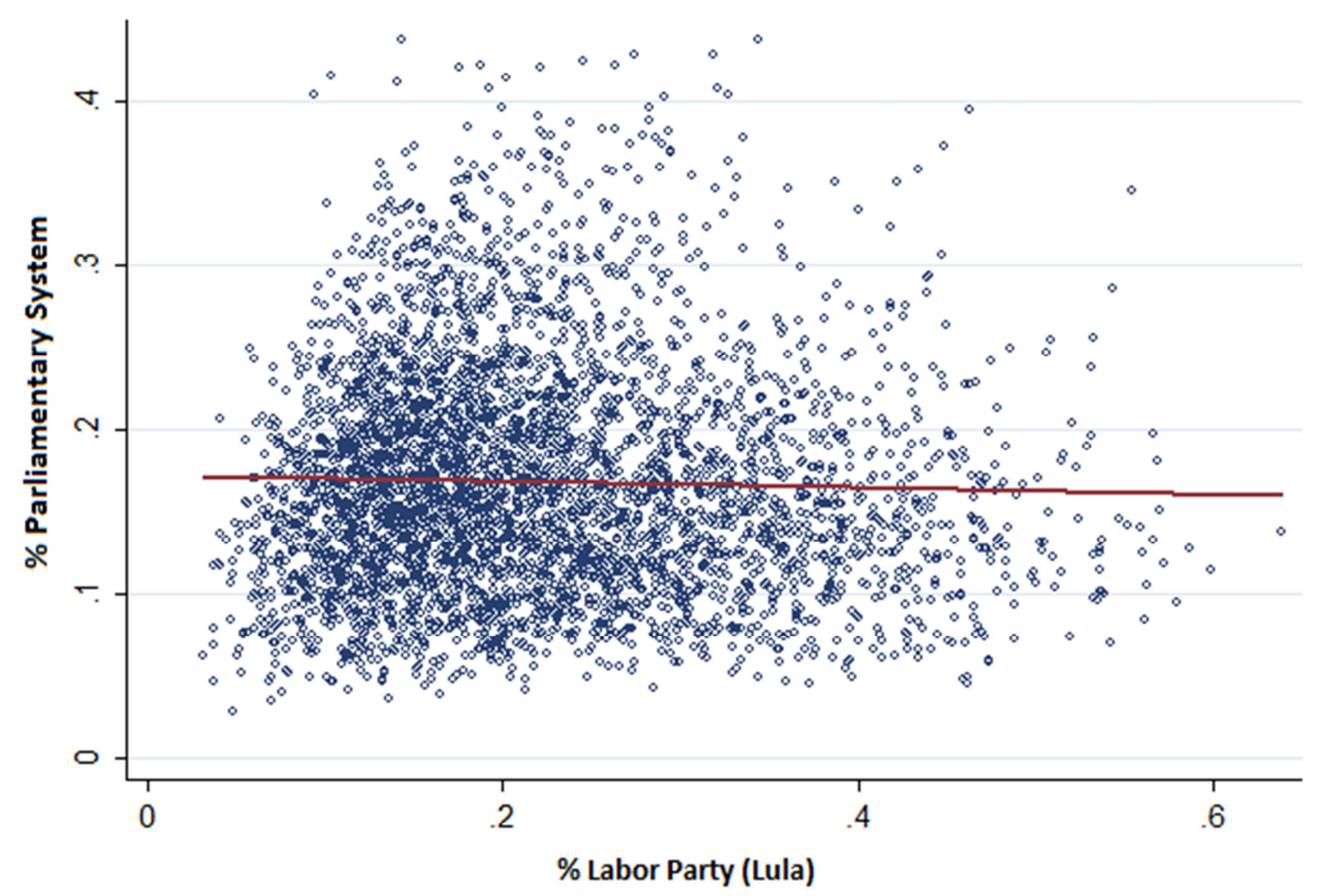

Note. This figure plots the relationship between the percentage of votes received by Luis Inacio Lula da Silva (Labor Party) in the presidential elections of 1994 and the percentage of votes cast for a parliamentary system. The graph displays a linear regression line with $\mathrm{R}^{2}=0$.

Figure 5: \% of Votes for a Parliamentary System versus \% of Votes for the Labor Party 


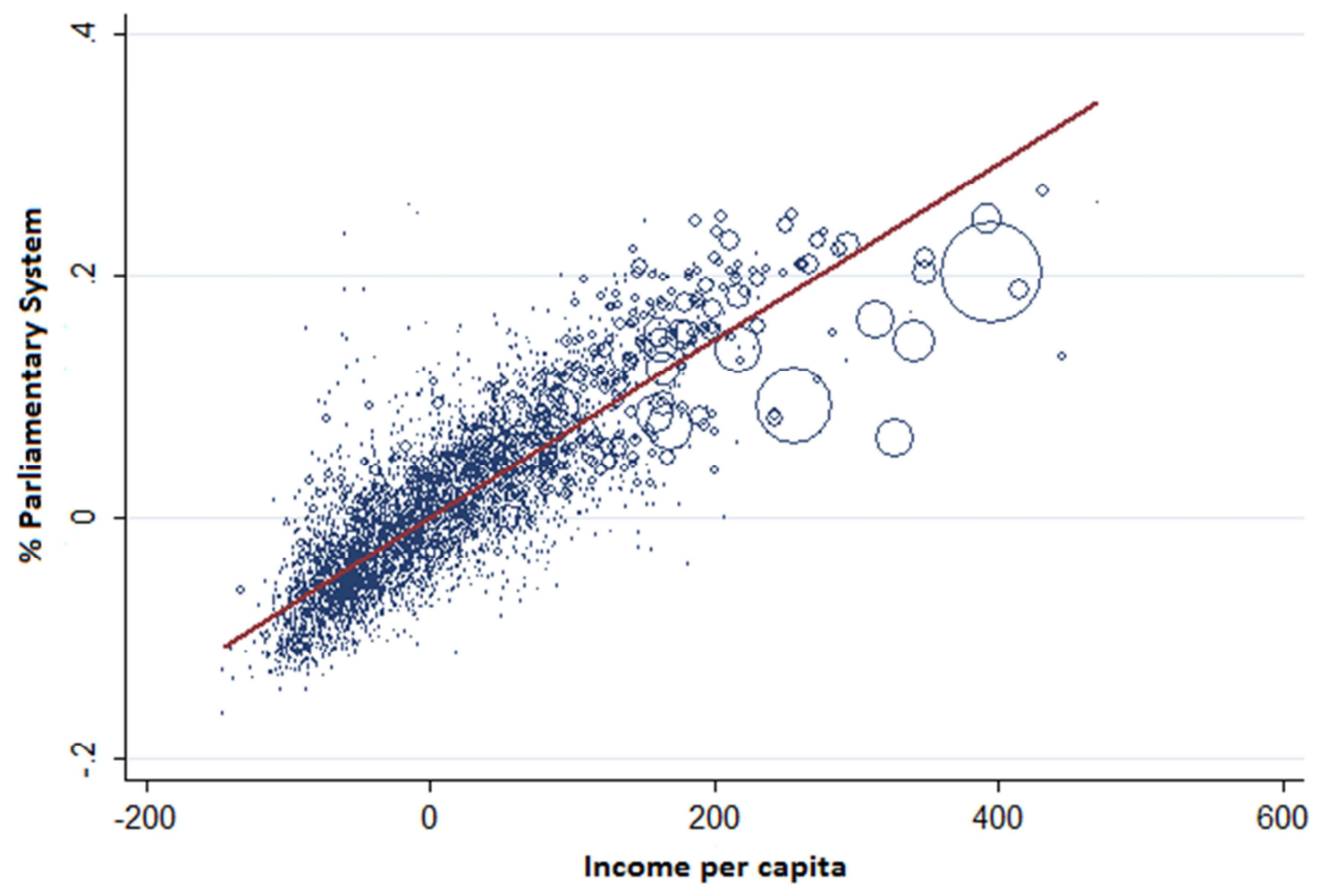

Note. This figure plots the relationship between income per capita and the percentage of votes cast for a parliamentary system, where we have partialled out the effect of the party affiliation of mayors. Each municipality is represented as a circle proportional to its population. The graph displays a linear regression line.

Figure 6: \% of Votes for a Parliamentary System versus Income per capita (partialled-out data) 


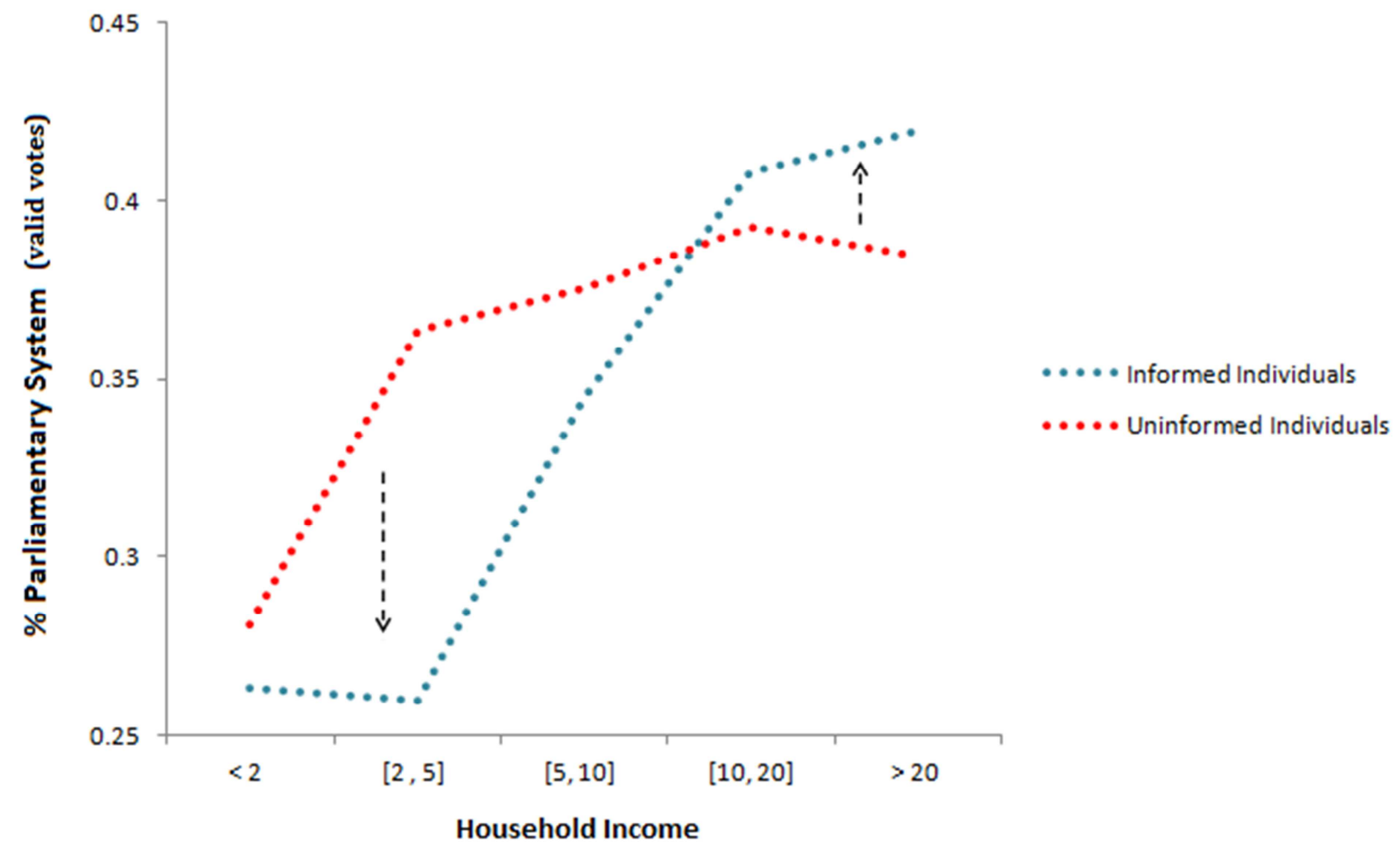

Note. This figure plots the voting intentions of informed and uninformed voters for different classes of household income (as measured in numbers of minimum wages). The informed individuals consist of those subjects who were able to correctly indentify (in spontaneous answers) at least two differences between presidential and parliamentary systems of government. The data refers to an opinion survey conducted by the Datafolha Institute on March $3^{\text {rd }}, 1993$.

Figure 7: Lack of Information Does Not Account for Stylized Facts 
In the parliamentary system there are several people ruling.

The Congress is corrupt.

Do not know how the parliamentary system works.

Do not know why would not vote for the parliamentary system.

Citizens do not have the right to elect the executive leader. / The members of the parliament are the ones who choose.

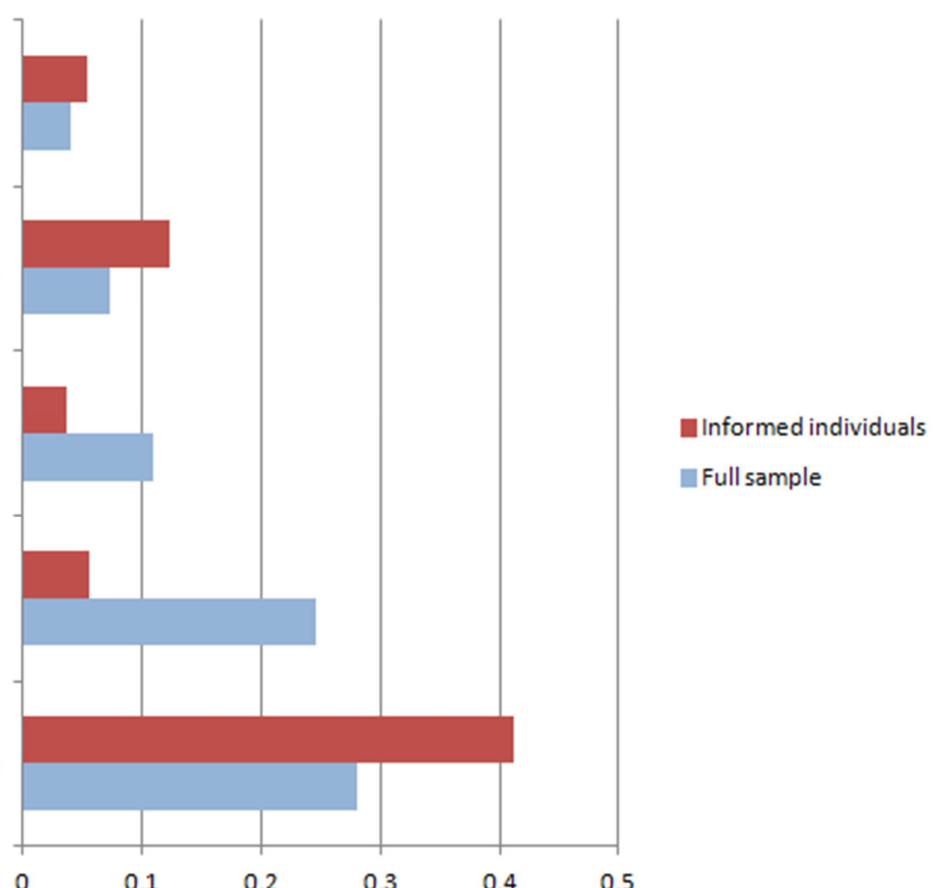

0.1

0.2

0.3

Note. This figure reports the most common reasons mentioned by voters when asked why they would not vote for a parliamentary system. The subsample of informed individuals consists of those subjects who were able to correctly indentify (in spontaneous answers) at least two differences between presidential and parliamentary systems. The data refers to an opinion survey conducted by the Datafolha Institute on March $3^{\text {rd }}, 1993$.

Figure 8: Why not a Parliamentary System? Common Reasons 


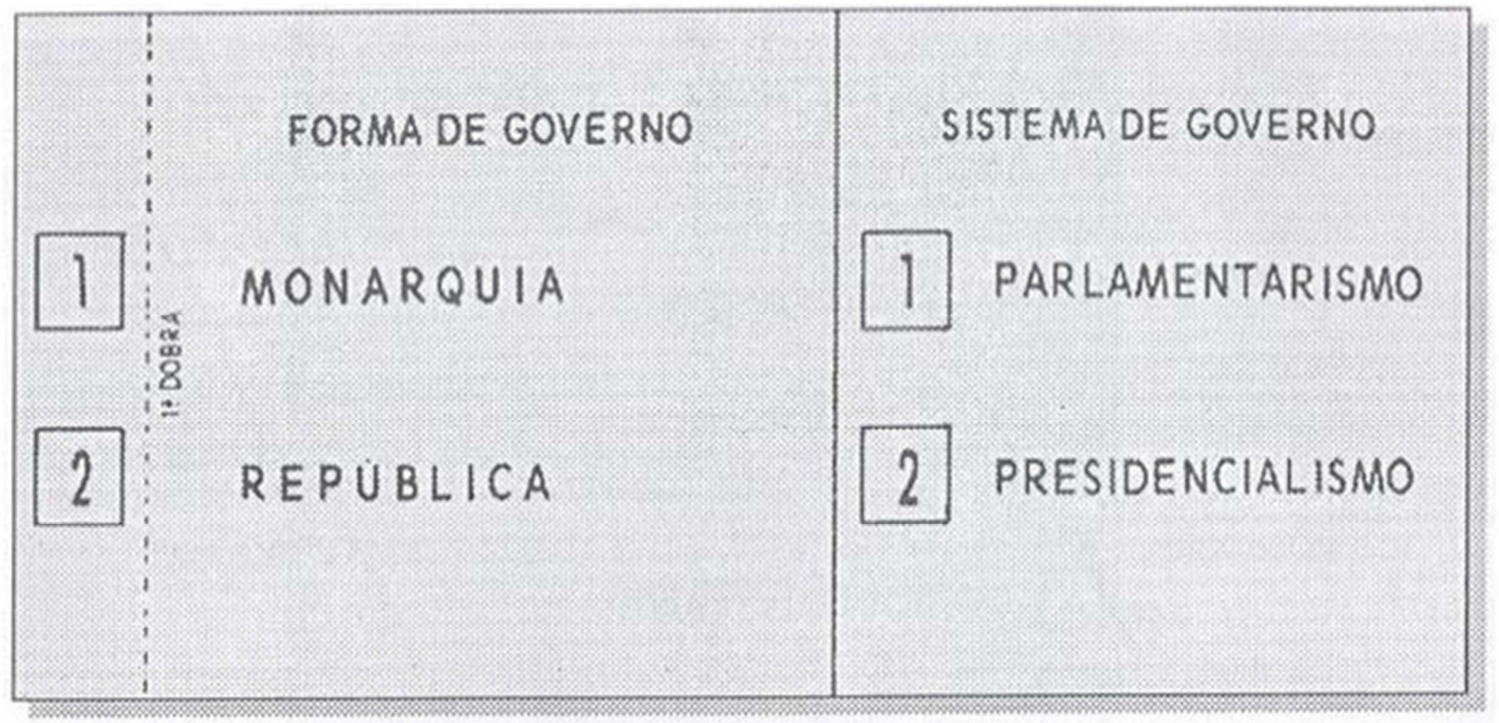

Note. This figure depicts the ballot paper used in the referendum. Voters were asked to choose between "monarchy" and "republic" as the "form of government" (left-hand side) and between "parliamentarism" and "presidentialism" as the "system of government" (right-hand side).

Figure A1: The Referendum Ballot Paper 


\begin{tabular}{lc}
\hline Form of Government & $\%$ \\
\hline Presidential system & 55,5 \\
Parliamentary system & 24,5 \\
Null or blank votes & 20,0 \\
\hline Notes. This table provides a summary of the \\
final outcome of Brazil's referendum of 1993. \\
The turnout rate was $75 \%$.
\end{tabular}

Table 1: Referendum: Final Result 


\begin{tabular}{|c|c|c|c|c|c|}
\hline & Obs. & Mean & S.D. & Min. & Max. \\
\hline \multicolumn{6}{|l|}{ Panel A. Cross-section of Municipalities } \\
\hline$\%$ parliamentary system & 4,144 & 0.167 & 0.068 & 0.029 & 0.438 \\
\hline \# AM radio stations & 4,144 & 0.31 & 0.72 & 0 & 10 \\
\hline federal judges and prosecutors & 4,144 & 0.03 & 0.18 & 0 & 1 \\
\hline log (income per capita) & 4,144 & 4.72 & 0.56 & 3.31 & 6.36 \\
\hline $\log$ (population) & 4,144 & 9.33 & 1.03 & 6.62 & 13.11 \\
\hline illiteracy rate & 4,144 & 0.286 & 0.160 & 0.018 & 0.892 \\
\hline gini coefficient & 4,144 & 0.53 & 0.05 & 0.34 & 0.79 \\
\hline \multicolumn{6}{|l|}{ Panel B. Survey Data } \\
\hline Voting intention: parliamentary system & 2,343 & 0.236 & 0.424 & 0 & 1 \\
\hline Household income: $<2 \mathrm{~min}$. wages & 2,343 & 0.232 & 0.422 & 0 & 1 \\
\hline Household income: 2 - $5 \mathrm{~min}$. wages & 2,343 & 0.261 & 0.439 & 0 & 1 \\
\hline Household income: $5-10 \mathrm{~min}$. wages & 2,343 & 0.227 & 0.419 & 0 & 1 \\
\hline Household income: $10-20 \mathrm{~min}$. wages & 2,343 & 0.134 & 0.340 & 0 & 1 \\
\hline Household income: $>20 \mathrm{~min}$. wages & 2,343 & 0.079 & 0.271 & 0 & 1 \\
\hline Household income: not reported & 2,343 & 0.064 & 0.244 & 0 & 1 \\
\hline Schooling: primary & 2,343 & 0.583 & 0.493 & 0 & 1 \\
\hline Schooling: secondary & 2,343 & 0.281 & 0.449 & 0 & 1 \\
\hline Schooling: superior & 2,343 & 0.135 & 0.342 & 0 & 1 \\
\hline Ideology: from left to right (scale $0-10$ ) & 2,343 & 5.85 & 2.56 & 0 & 10 \\
\hline Trust in the congress: Very low & 2,343 & 0.310 & 0.462 & 0 & 1 \\
\hline $\begin{array}{l}\text { Do you think that the country would be better off if the military } \\
\text { returned to power? Yes. }\end{array}$ & 2,343 & 0.361 & 0.480 & 0 & 1 \\
\hline
\end{tabular}

Table 2: Summary Statistics 


\begin{tabular}{lcc}
\hline & Full Sample & Informed Individuals \\
\cline { 2 - 3 } \% parliamentary system & 25,7 & $28,1[+2.4 \%]$ \\
$\%$ presidential system & 51,9 & $58,7[+6.8 \%]$ \\
$\%$ undecided & 22,3 & $13,1[-9.2 \%]$ \\
observations & 2.607 & 1.059 \\
\hline
\end{tabular}

Notes. This table provides a summary of the voting intentions for subjects in the full sample and in the subsample of informed individuals. The subgroup of informed individuals consists of those voters who were able to correctly identify (in spontaneous answers) at least two differences between presidential and parliamentary systems. The numbers in brackets correspond to the difference (in terms of percentage points) between the voting intentions of the two groups. The data refer to an opinion survey conducted by the Datafolha Institute on March 3rd, 1993.

Table 3: Information about the Referendum 


\begin{tabular}{lcccc}
\hline Dependent Variable: \% parliamentary system & & & & \\
& {$[1]$} & {$[2]$} & {$[3]$} & {$[4]$} \\
\hline number of AM radio stations & $0.007^{* * *}$ & $0.007^{* * *}$ & & \\
& {$[0.001]$} & {$[0.001]$} & & \\
presence of federal judges and prosecutors & & & $0.013^{* * *}$ & $0.013^{* * *}$ \\
& & & {$[0.004]$} & {$[0.004]$} \\
$\log$ (income per capita) & $0.057^{* * *}$ & $0.058^{* * *}$ & $0.058^{* * *}$ & $0.059^{* * *}$ \\
& {$[0.003]$} & {$[0.003]$} & {$[0.003]$} & {$[0.003]$} \\
log(population) & $0.007^{* * *}$ & $0.007^{* * *}$ & $0.009^{* * *}$ & $0.009^{* * *}$ \\
& {$[0.001]$} & {$[0.001]$} & {$[0.001]$} & {$[0.001]$} \\
illiteracy rate & $-0.073^{* * *}$ & $-0.073^{* * *}$ & $-0.077^{* * *}$ & $-0.076^{* * *}$ \\
& {$[0.016]$} & {$[0.016]$} & {$[0.016]$} & {$[0.001]$} \\
Gini coefficient (income) & $-0.081^{* * *}$ & $-0.080^{* * *}$ & $-0.076^{* * *}$ & $-0.074^{* * *}$ \\
& {$[0.015]$} & {$[0.005]$} & {$[0.015]$} & {$[0.015]$} \\
\hline municipal characteristics & $\mathrm{Y}$ & $\mathrm{Y}$ & $\mathrm{Y}$ & $\mathrm{Y}$ \\
state fixed effects & $\mathrm{Y}$ & $\mathrm{Y}$ & $\mathrm{N}$ & $\mathrm{Y}$ \\
mayor's party fixed effects & $\mathrm{N}$ & $\mathrm{Y}$ & $\mathrm{N}$ & $\mathrm{Y}$ \\
observations & 4,145 & 4,096 & 4,149 & 4,099 \\
$\mathrm{R}^{2}$ & 0.69 & 0.70 & 0.69 & 0.7 \\
\hline
\end{tabular}

Notes. This table reports OLS estimates for regressions where the dependent variable is the percentage of valid votes cast for a parliamentary system in each municipality. Municipal characteristics include: percentage of the population living in rural areas, population density (inhabitants $/ \mathrm{km}^{2}$ ), state capital dummy, distance to the state capital, percentage of abstention, percentage of null votes and percentage of votes cast for the PMDB, the PSDB and the PT candidates in the 1994 presidential elections. All regressions include state fixed effects. Additionally, the regressions reported in columns [2] and [4] include dummies for the mayor's party affiliation. The sample comprehends all municipalities with population less than 500,000 citizens. Robust standard errors are reported in brackets. ${ }^{* * *},{ }^{* *}$ and ${ }^{*}$ denote significance at $10 \%, 5 \%$ and $1 \%$, respectively.

\section{Table 4: OLS Regressions: Cross-section of Municipalities}


Dependent variable: parliamentary system (0/1)

\begin{tabular}{|c|c|c|}
\hline method: & \multirow{2}{*}{$\begin{array}{r}\text { Logit } \\
{[1]}\end{array}$} & \multirow{2}{*}{$\begin{array}{r}\text { Logit } \\
{[2]}\end{array}$} \\
\hline & & \\
\hline \multirow[t]{2}{*}{ Household income: 2 - 5 min. wages } & -0.0003 & -0.015 \\
\hline & {$[0.161]$} & {$[0.170]$} \\
\hline \multirow[t]{2}{*}{ Household income: 5 - 10 min. wages } & $0.410^{* * *}$ & $0.335 *$ \\
\hline & {$[0.160]$} & {$[0.175]$} \\
\hline \multirow[t]{2}{*}{ Household income: 10 - 20 min. wages } & $0.437^{* *}$ & 0.328 \\
\hline & {$[0.190]$} & {$[0.204]$} \\
\hline \multirow[t]{2}{*}{ Household income: > 20 min. wages } & $0.660^{* * *}$ & $0.533^{* *}$ \\
\hline & {$[0.219]$} & {$[0.240]$} \\
\hline \multirow[t]{2}{*}{ Ideology: from left to right (scale $0-10$ ) } & $-0.051 * *$ & $-0.052 * *$ \\
\hline & {$[0.022]$} & {$[0.22]$} \\
\hline \multirow[t]{2}{*}{ Trust in the congress: Very low } & $-0.211 *$ & $-0.247^{* *}$ \\
\hline & {$[0.112]$} & [0.119] \\
\hline \multirow{2}{*}{$\begin{array}{l}\text { Do you think that the country would be better off if the military } \\
\text { returned to power? Yes. }\end{array}$} & 0.141 & 0.129 \\
\hline & {$[0.112]$} & {$[0.116]$} \\
\hline municipality fixed effects & $\mathrm{N}$ & $\mathrm{Y}$ \\
\hline individual characteristics & $\mathrm{Y}$ & $\mathrm{Y}$ \\
\hline observations & 2,178 & 2,084 \\
\hline
\end{tabular}

Notes. This table reports logit regressions where the dependent variable is a dummy indicating whether the person intends to vote for a parliamentary system. The data used in the analysis refer to an opinion survey conducted by the Datafolha Institute on March 28th, 1993. Individual characteristics include: gender, age, age squared, two dummy variables indicating the candidate voted in the second round of the 1989 presidential elections (Fernando Collor de Mello or Luis Inacio Lula da Silva), two dummy variables indicating whether the person knows the name of the president and the name of the state's governor and four dummy variables indicating whether the person is religious, favours abortion, favours death penalty and serves in local communities. $* * * * *$ and $*$ denote significance at $10 \%, 5 \%$ and $1 \%$, respectively.

\section{Table 5: Survey Data}

